Article

\title{
Synthesis and Biological Evaluation of Benzochromenopyrimidinones as Cholinesterase Inhibitors and Potent Antioxidant, Non-Hepatotoxic Agents for Alzheimer's Disease
}

\author{
Youssef Dgachi ${ }^{1}$, Oscar M. Bautista-Aguilera ${ }^{2}$, Mohamed Benchekroun ${ }^{2,+}{ }^{\text {, Hélène Martin }}{ }^{3}$, \\ Alexandre Bonet ${ }^{3}$, Damijan Knez ${ }^{4}$, Justyna Godyń ${ }^{5}$, Barbara Malawska ${ }^{5}$, Stanislav Gobec ${ }^{4}$, \\ Mourad Chioua ${ }^{6}$, Jana Janockova ${ }^{7}$, Ondrej Soukup ${ }^{7}$, Fakher Chabchoub ${ }^{1, *}$, \\ José Marco-Contelles ${ }^{6, *}$ and Lhassane Ismaili ${ }^{2, *}$ \\ 1 Laboratory of Applied Chemistry, Heterocycles, Lipids and Polymers, Faculty of Sciences of Sfax, \\ University of Sfax, B.P. 802, Sfax 3000, Tunisia; youssefdgachi@gmail.com \\ 2 Laboratoire de Chimie Organique et Thérapeutique, Neurosciences Intégratives et Cliniques, EA 481, \\ UFR SMP, Univ. Franche-Comté, Univ. Bourgogne Franche-Comté, 19, rue Ambroise Paré, \\ Besançon F-25000, France; osmabaga@gmail.com (O.M.B.-A.); mohamed.benchekroun@outlook.com (M.B.) \\ 3 Laboratory of Cell Toxicology, EA 4267, University of Bourgogne Franche-Comté, 19 rue Ambroise Paré, \\ Besançon Cedex 25030, France; helene.martin@univ-fcomte.fr (H.M.); alexandre.bonet@univ-fcomte.fr (A.B.) \\ 4 Faculty of Pharmacy, University of Ljubljana, Aškerčeva 7, Ljubljana 1000, Slovenia; \\ damijan.knez@ffa.uni-lj.si (D.K.); stanislav.gobec@ffa.uni-lj.si (S.G.) \\ 5 Department of Physicochemical Drug Analysis, Jagiellonian University Medical College, Medyczna 9 Street, \\ Krakow 30-688, Poland; justyna.godyn@uj.edu.pl (J.G.); mfmalaws@cyf-kr.edu.pl (B.M.) \\ 6 Laboratory of Medicinal Chemistry (IQOG, CSIC) C/Juan de la Cierva 3, Madrid 28006, Spain; \\ mchioua@gmail.com \\ 7 Biomedical Research Center, University Hospital Hradec Kralove, 50005 Hradec Králove, Czech Republic; \\ jana.janockova@fnhk.cz (J.J.); soukup.ondrej@fnhk.cz (O.S.) \\ * Correspondence: fakher.chabchoub@yahoo.fr (F.C.); iqoc21@iqog.csic.es (J.M.-C.); \\ lhassane.ismaili@univ-fcomte.fr (L.I.); Tel.: +216-7467-6606 (F.C.); +34-9-1562-2900 (J.M.-C.); +33-3-8166-5543 (L.I.) \\ + Present Address: Centre de Recherche de Gif-sur-Yvette, Institut de Chimie des Substances Naturelles, \\ UPR 2301, CNRS, Avenue de la Terrasse, Gif-sur-Yvette 91198, France.
}

Academic Editors: Michael Decker and Diego Muñoz-Torrero

Received: 18 February 2016; Accepted: 4 May 2016; Published: 14 May 2016

\begin{abstract}
We report herein the straightforward two-step synthesis and biological assessment of novel racemic benzochromenopyrimidinones as non-hepatotoxic, acetylcholinesterase inhibitors with antioxidative properties. Among them, compound $\mathbf{3 B b}$ displayed a mixed-type inhibition of human acetylcholinesterase $\left(\mathrm{IC}_{50}=1.28 \pm 0.03 \mu \mathrm{M}\right)$, good antioxidant activity, and also proved to be non-hepatotoxic on human HepG2 cell line.
\end{abstract}

Keywords: Alzheimer's disease; quinazolinones; multicomponent reactions; multitarget-directed ligands; antioxidants; cholinesterase inhibitors; hepatotoxicity

\section{Introduction}

Alzheimer's disease (AD) has emerged as the main cause of memory and cognitive deficiency in aged persons. The Alzheimer's disease International (ADI) Association report from 2015 estimates that over 46 million people are currently affected by dementia. Given the epidemic expansion of $\mathrm{AD}$, this number is expected to drastically increase in the future, reaching 131.5 million cases by 2050 [1]. Many efforts have been devoted to comprehend the complex etiology of AD, yet certain aspects of the pathogenesis are still not well understood. Nevertheless, several histopathologic 
features have been clearly identified in AD patients such as intracellular neurofibrillary tangles, composed of hyperphosphorylated tau protein and toxic amyloid plaques of aggregated $\beta$-amyloid (A $\beta$ ) peptide. Moreover, different levels of neuronal loss have been observed in the Locus coeruleus [2], Nucleus basalis [3] and Substantia nigra [4] brain areas, leading to substantial perturbations in several neurotransmission systems such as the cholinergic, serotoninergic, GABAergic, glutamatergic, noradrenergic or dopaminergic system.

Oxidative stress holds a fundamental position in the onset and development of AD. Several studies have confirmed that the constant accumulation of reactive oxygen species and reactive nitrogen species leads inevitably to serious oxidative damage in neuronal tissues [5]. This oxidative stress can be triggered by different underlying factors such as mitochondrial dysfunction [6], loss of metal homeostasis (e.g., $\mathrm{Cu}^{2+}, \mathrm{Fe}^{2+}, \mathrm{Zn}^{2+}$ ), the involvement of the later ions in $\mathrm{A} \beta$ aggregation [7], and neuroinflammation [8]. Globally, there is unanimity to consider these different biological events all at once, and address the unmet need for an efficient anti-AD agent.

In terms of medication use, the currently marketed drugs are mainly inhibitors of cholinesterases (ChEIs) (acetylcholinesterase, AChE; and butyrylcholinesterase, BuChE). These are donepezil, rivastigmine, and galantamine [9], which enhance the levels of neurotransmitter acetylcholine in the synaptic cleft. The only drug with a different mechanism of action is memantine, a $N$-methyl-D-aspartate receptor antagonist [10]. One of the first marketed ChEI, tacrine, was rapidly withdrawn, principally because of its hepatotoxicity [11]. Globally, the therapeutic efficacy of pure ChEIs may be brought into question since only scarce improvements in memory and cognitive functions have been reached in $\mathrm{AD}$ patients, with no signs of clear reversal of the disease. Therefore, the design of new multitarget-directed ligands represents one of the most promising approaches for the development of new disease-modifying agents for AD therapy [12-14]. Indeed, compounds capable to simultaneously modulate various biological systems in relation with $\mathrm{AD}$ pathogenesis might be a winning strategy in the future by furnishing fine-tuned drug candidates for the clinics.

Several series of quinazolinone derivatives have already been developed, inspired by naturally occurring alkaloids deoxyvasicinone (Ia), dehydroevodiamine chloride (II), evodiamine (III) and rutaecarpine (IV) (Figure 1), with promising inhibition of ChEs [15-17]. Further SAR investigations were done and revealed that some new carbamate analogues of evodiamine were selective butyrylcholinesterase inhibitors (BuChEIs), potent antioxidants and neuroprotective agents against glutamate-induced oxidative stress in HT-22 cells [16].
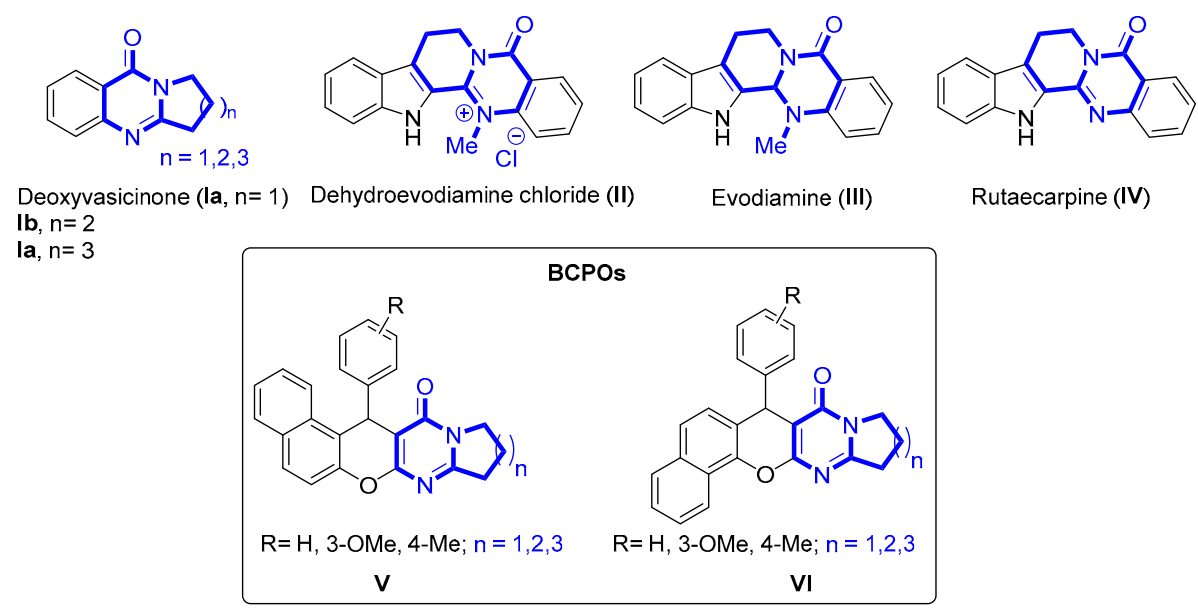

Rutaecarpine (IV)

Figure 1. The quinazolinone alkaloids Ia-IV and designed BCPOs V and VI.

In relation with these antecedents and with our earlier work [18,19], we applied a multicomponent reaction approach to further explore the chemical space based on the quinazolinone scaffold. Thus, we have designed new benzochromenopyrimidinones of type $\mathbf{V}$ and VI (abbreviated as BCPOs, Figure 1), 
where a benzochromene motif was fused to the pyrimidinone motif present in alkaloids Ia-IV. As a result, eighteen new BCPOs were synthesized and evaluated for their antioxidant activity, ChE inhibition, and their in vitro toxicity in liver HepG2. From these studies, we have identified compound $\mathbf{3 B b}$ as a promising derivative potentially useful in further AD drug discovery steps.

\section{Results and Discussion}

\subsection{Synthesis}

The synthesis of the target BCPOs 3 and 4 has been carried out in two steps, and good overall yields as outlined in Scheme 1. First, a microwave-assisted multicomponent reaction of ethyl cyanoacetate, selected aromatic aldehydes, and 2- or 1-naphthol, in the presence of a catalytic amount of piperidine in ethanol, at $80{ }^{\circ} \mathrm{C}$, for $10 \mathrm{~min}$, gave the corresponding ethyl 3-amino-1-phenyl-1H-benzo[ $f$ chromene-2-carboxylates 1A-C or ethyl 2-amino-4-phenyl-4H-benzo[ $h$ ]chromene-3-carboxylates 2A-C, respectively, in good yields $(68 \%-90 \%)$. The second step was the condensation of adducts $\mathbf{1 A}-\mathbf{C}$ or $\mathbf{2 A}-\mathbf{C}$ with the appropriate commercial lactams, in the presence of phosphorus oxytrichloride in 1,2-dichloroethane, under microwave irradiation for $15 \mathrm{~min}$ at $80{ }^{\circ} \mathrm{C}$, to give compounds 3 and 4 in high yields (70\%-96\%). All new compounds displayed satisfactory analytical and spectroscopic data correlating with their structure, and with the data reported in the literature for comparable molecules (see Experimental Section).
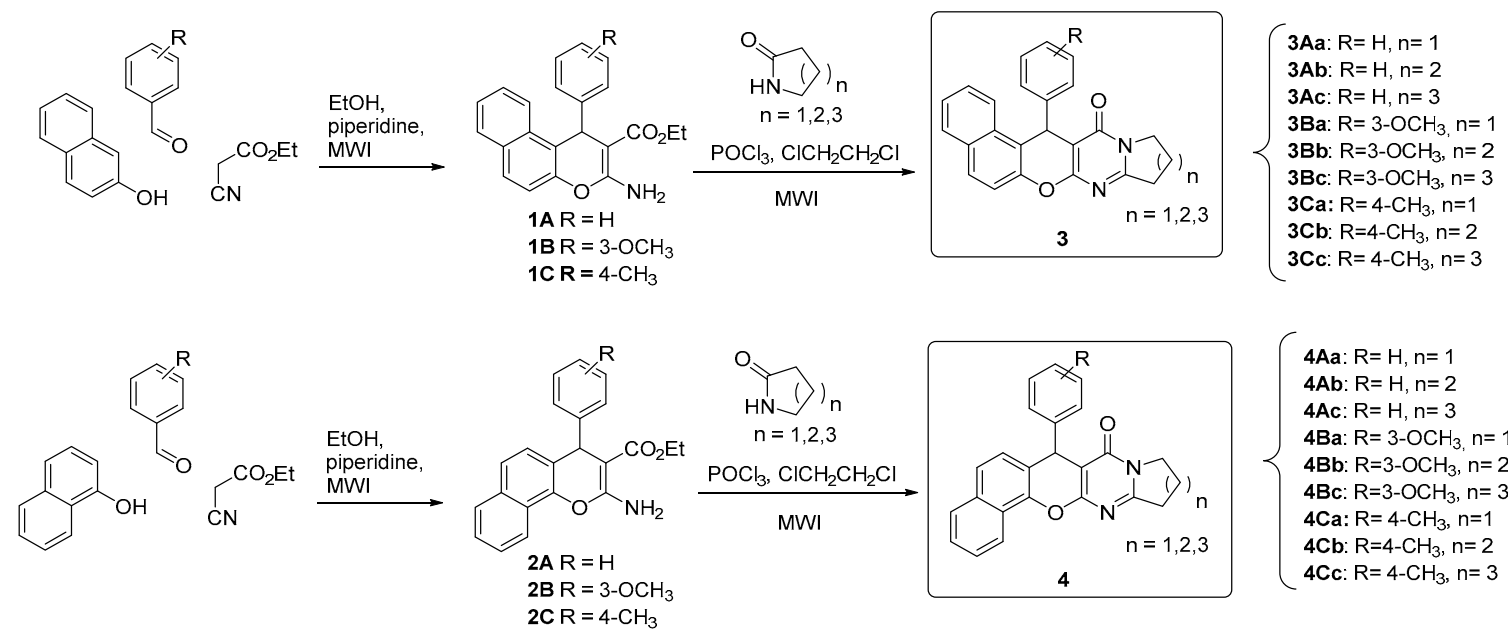

4Aa: $R=H, n=1$ $4 A b: R=H, n=2$ 4Ac: $\mathrm{R}=\mathrm{H}, \mathrm{n}=3$ 4Ba: $\mathrm{R}=3-\mathrm{OCH}_{3}, \mathrm{n}=1$ 4Bb: $\mathrm{R}=3-\mathrm{OCH}_{3}, \mathrm{n}=2$ 4Bc: $\mathrm{R}=3-\mathrm{OCH}_{3}, \mathrm{n}=3$ 4Ca: $\mathrm{R}=4-\mathrm{CH}_{3}, \mathrm{n}=1$ 4Cb: $\mathrm{R}=4-\mathrm{CH}_{3}, \mathrm{n}=2$

Scheme 1. Synthesis of BCPOs 3 and 4.

\subsection{Evaluation of the Antioxidant Power}

First of all, we evaluated the antioxidant activity of compounds 3 and 4 using the oxygen radical absorbance capacity by fluorescence (ORAC-FL) method [20,21]. Trolox was used as standard, fluorescein as fluorescent probe and 2,2'-azobis(2-amidinopropane) dihydrochloride (AAPH) as the peroxyl radical source. Ferulic acid was used as a positive control [22]. Data were expressed as Trolox equivalents (TE), and as shown in table 1, all compounds were able to scavenge the peroxyl radical with ORAC values ranging between 2.3 and $4.7 \mathrm{TE}$. The unsubstituted adducts $\mathbf{3 A a}-\mathbf{c}, \mathbf{4 A a}-\mathbf{c}$ were found to be slightly less potent than the analogues bearing methoxy and methyl groups at the aromatic ring, with values ranging between 2.1 and 2.6 TE. However, when the phenyl moiety was substituted by a methoxy group, we globally observed a better antioxidant activity, compound $\mathbf{3 B b}$ being the most active (4.7 TE) and displaying enhanced antioxidant activity compared to ferulic acid (3.7 TE). 


\subsection{Evaluation of $A C h E$ and BuChE Inhibition}

For the preliminary screening of the inhibitory potencies, Electrophorus electricus AChE (EeAChE) and horse serum BuChE (eqBuChE) were used following the Ellman's assay [23]. Tacrine, able to inhibit both ChEs, was selected as a control. First of all, compounds 3 and 4 were poor $e q B u C h E I s$, and due to the limited solubility in the assay medium, only the percentage of inhibition at $10 \mu \mathrm{M}$ was determined. However, these compounds exhibited encouraging inhibitory potencies against EeAChE with $\mathrm{IC}_{50}$ values ranging from 30.5 to $518.4 \mathrm{nM}$. The most potent EeAChEIs, in decreasing order, were compounds $3 \mathbf{B b}, 3 \mathrm{Ab}, 3 \mathbf{C b}$ and $3 \mathbf{B a}$ with $\mathrm{IC}_{50} 30.5,55.5,55.9$ and $60.7 \mathrm{nM}$ values, respectively, showing activities comparable to that of tacrine $\left(\mathrm{IC}_{50}=44.3 \mathrm{nM}\right)$. Very interestingly, and for comparative purposes, related natural alkaloids Ia [24] or II [15], and synthetic compounds Ib,c [24] are poorer EeAChEIs than BCPOs 3 and 4 (Table 1).

Table 1. Inhibitions of EeAChE, eqBuChE, $h \mathrm{AChE}$ and ORAC-FL values for compounds 3 and 4.
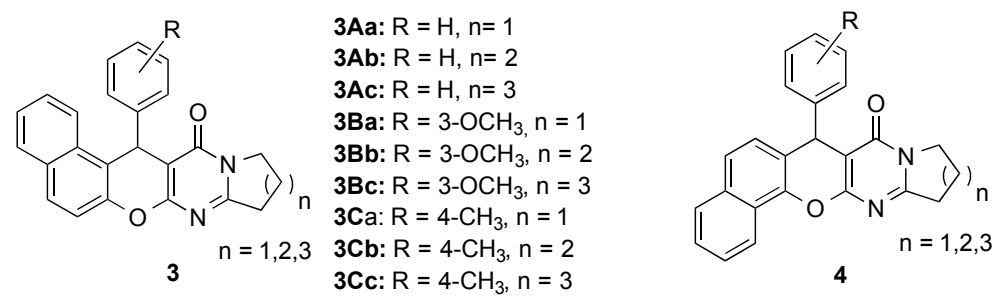

4Aa: $R=H, n=1$
4Ab: $R=H, n=2$
4Ac: $R=H, n=3$
4Ba: $R=3-\mathrm{OCH}_{3}, n=1$
4Bb: $R=3-\mathrm{OCH}_{3}, n=2$
4Bc: $R=3-\mathrm{OCH}_{3}, n=3$
4Ca: $R=4-\mathrm{CH}_{3}, n=1$
4Cb: $R=4-\mathrm{CH}_{3}, n=2$
4Cc: $R=4-\mathrm{CH}_{3}, n=3$

\begin{tabular}{|c|c|c|c|c|}
\hline ВСРО & $\operatorname{EeAChE}{ }^{1}\left(\mathrm{IC}_{50}, \mathrm{nM}\right)$ & $e q \mathrm{BuChE}(\%$ Inhibition at $10 \mu \mathrm{M})$ & $h \mathrm{AChE}\left(\mathrm{IC}_{50}, \mathrm{nM}\right)$ & ORAC $^{2}$ \\
\hline 3Aa & $518.4 \pm 87.9$ & $12.1 \pm 1.4$ & n.d. & $2.6 \pm 0.1$ \\
\hline $3 \mathrm{Ab}$ & $55.5 \pm 7.1$ & $31.2 \pm 1.8$ & $3657 \pm 59$ & $2.3 \pm 0.3$ \\
\hline $3 \mathrm{Ac}$ & $300.8 \pm 6.5$ & $28.4 \pm 7.3$ & n. $\bar{d}$. & $2.5 \pm 0.2$ \\
\hline $3 B \mathbf{a}$ & $60.7 \pm 4.5$ & $51.0 \pm 4.0$ & $1527 \pm 25$ & $3.4 \pm 0.2$ \\
\hline $3 \mathrm{Bb}$ & $30.5 \pm 2.8$ & $43.0 \pm 1.9$ & $1279 \pm 32$ & $4.7 \pm 0.2$ \\
\hline $3 B c$ & $107.5 \pm 7.2$ & n.a. & n.d. & $3.5 \pm 0.3$ \\
\hline $3 \mathrm{Ca}$ & $111.9 \pm 21.7$ & $17.4 \pm 1.8$ & n.d. & $2.7 \pm 0.3$ \\
\hline $3 \mathrm{Cb}$ & $55.9 \pm 12.7$ & $19.0 \pm 2.0$ & $1591 \pm 24$ & $3.9 \pm 0.3$ \\
\hline $3 \mathrm{Cc}$ & $166.6 \pm 7.8$ & n.a. & n.d. & $3.1 \pm 0.2$ \\
\hline $4 \mathrm{Aa}$ & $317.8 \pm 26.0$ & $23.1 \pm 3.1$ & n.d. & $2.1 \pm 0.1$ \\
\hline $4 \mathrm{Ab}$ & $383.5 \pm 19.4$ & $54.6 \pm 1.8$ & n.d. & $2.3 \pm 0.2$ \\
\hline 4Ac & $290.5 \pm 8.3$ & $24.2 \pm 3.1$ & n.d. & $2.5 \pm 0.1$ \\
\hline $4 B a$ & $326.7 \pm 38.9$ & $38.0 \pm 1.6$ & n.d. & $3.8 \pm 0.1$ \\
\hline $4 \mathrm{Bb}$ & $153.2 \pm 3.1$ & n.a. & n.d. & $3.7 \pm 0.2$ \\
\hline $4 \mathrm{Bc}$ & $195.3 \pm 6.2$ & $31.1 \pm 2.1$ & n.d. & $3.4 \pm 0.2$ \\
\hline $4 \mathrm{Ca}$ & $115.8 \pm 6.2$ & $26.8 \pm 2.9$ & n.d. & $3.2 \pm 0.1$ \\
\hline $4 \mathrm{Cb}$ & $193.4 \pm 18.7$ & $24.4 \pm 1.2$ & n.d. & $2.9 \pm 0.1$ \\
\hline $4 \mathrm{Cc}$ & $173.8 \pm 5.9$ & n.a. & n.d. & $3.6 \pm 0.2$ \\
\hline Tacrine & $44.3 \pm 1.5[19]$ & $\mathrm{IC}_{50}=5.1 \pm 0.2 \mathrm{nM}[19]$ & $131 \pm 2$ & $0.2 \pm 0.1[22]$ \\
\hline Ia & $82.5 \mathrm{M}[24]$ & $\mathrm{IC}_{50}=25.1[24]$ & n.d. & n.d. \\
\hline Ib & $38.6 \mathrm{M}[24]$ & $>500[24]$ & n.d. & n.d. \\
\hline Ic & $279 \mathrm{M}[24]$ & $>500[24]$ & n.d. & n.d. \\
\hline II & 6.3 M [15] & $\mathrm{IC}_{50}=8.4 \mathrm{M}[15]$ & n.d. & n.d. \\
\hline Ferulic acid & n.d. & n.d. & n.d. & $3.7 \pm 0.1[22]$ \\
\hline
\end{tabular}

${ }^{1} \mathrm{IC}_{50}$ values were obtained by nonlinear regression. Ee: electric eel, eq: serum horse, $h$ : human. Each $\mathrm{IC}_{50}$ value is the mean \pm SEM of at least three independent experiments. ${ }^{2}$ Data are expressed as Trolox equivalents and are shown as mean \pm SD. n.a.: Not active (any inhibition was observed). n.d.: not determined.

When examining the structure-activity relationships (SAR), we could observe that the four most active compounds $(\mathbf{3 A b}, \mathbf{3 B b}, \mathbf{3} \mathbf{C b}$ and $\mathbf{3 B a}$ ) belong to the $\mathbf{V}$ family (Figure 1$)$. Concerning the size of the saturated carbocyclic ring attached to the pyrimidinone moiety and considering the same substituent on the aromatic ring attached at the stereogenic center, the most potent AChEIs were compounds bearing a piperidine-fused ring $(3 \mathbf{A b}, \mathbf{3 B b}$, and $\mathbf{3 C b})$ for the $\mathbf{V}$ family. For the VI type derivatives, no evident SAR could have been established. Finally, we can notice that BCPOs of type V, with a methoxy-substituted benzene ring had $\mathrm{IC}_{50}$ values for the inhibition of EeAChE much higher than non-substituted analogues. 
Based on these findings, we selected compounds $\mathbf{3 A b}, \mathbf{3 B b}, \mathbf{3} \mathbf{C b}$ and $\mathbf{3} \mathbf{B a}$ for the $\mathrm{A} \beta_{1-42}$ aggregation inhibition studies. Unfortunately, only compound $\mathbf{3 A b}$ showed a weak inhibition power (Supplementary Materials). Next, we investigated the ability of compounds $\mathbf{3 A b}, \mathbf{3 B b}, \mathbf{3 C b}$ and $\mathbf{3 B} \mathbf{B a}$ to inhibit human recombinant $\mathrm{AChE}(h \mathrm{AChE})$, and their liver toxicity.

\subsection{Kinetic Study of the hAChE Inhibition by Compound 3Bb}

As shown in Table 1, we found significantly lower inhibition for $h$ AChE in comparison with $\mathrm{EeAChE}$, the $\mathrm{IC}_{50}$ values ranging from 1279 to $3657 \mathrm{nM}$. Compound $3 \mathrm{Bb}$ was the most potent inhibitor with an $\mathrm{IC}_{50}$ value of $1279 \mathrm{nM}$.

To get insight into the mode of inhibition, the kinetic mechanism of $h \mathrm{AChE}$ inhibition by compound $\mathbf{3 B b}$ was investigated through classical Lineweaver-Burk double reciprocal plots. Analysis of this plot (Figure 2) showed the interception of the lines above the $x$-axis indicating that $\mathbf{3 B b}$ is able to interact with both the free and acylated enzyme, and therefore behaves as mixed-type inhibitor of $h \mathrm{AChE}$. The inhibitor dissociation constants $K_{i}$ (dissociation constant for the enzyme-inhibitor complex) and $K_{i}^{\prime}$ (dissociation constant for the enzyme-inhibitor-substrate complex) were estimated and were 0.38 and $1.12 \mu \mathrm{M}$, respectively.

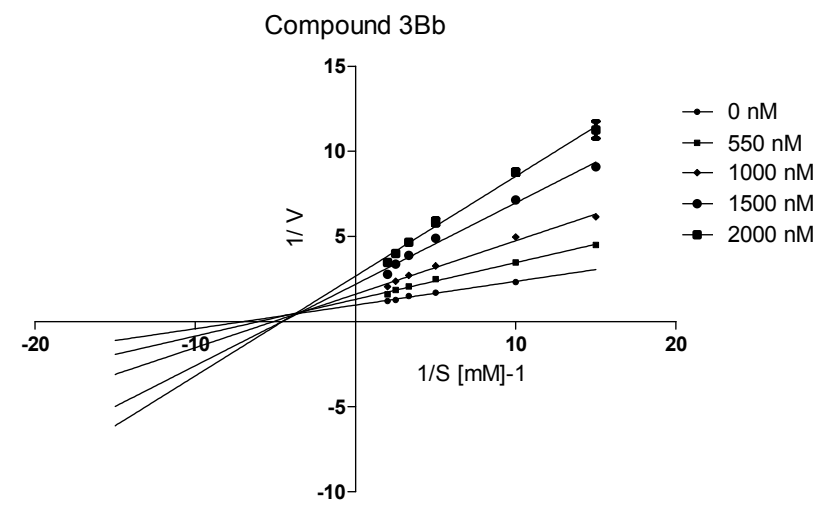

Figure 2. Lineweaver-Burk double reciprocal plot demonstrating mixed-type of $h \mathrm{AChE}$ inhibition by compound $3 \mathbf{B b}$. $S$ = acetylthiocholine; $V=$ initial velocity rate.

\subsection{In Vitro Toxicity of Compounds $\mathbf{3 A b}, \mathbf{3 B b}, \mathbf{3 C b}$ and $\mathbf{3 B a}$ in Hep G2 Cells}

A prerequisite for any effective lead drug is to keep its cytotoxicity at the lowest possible level. In this regard, we submitted the four most promising compounds $(\mathbf{3 A b}, \mathbf{3 B b}, \mathbf{3} \mathbf{C b}$ and $\mathbf{3 B a})$ to an in vitro toxicologic evaluation (MTT assay) using human hepatocellular carcinoma cell line (HepG2) which represents a good probe to evaluate hepatotoxic effects. As shown in Table 2, tacrine was safe up to $100 \mu \mathrm{M}$ but significantly decreased cell viability above $300 \mu \mathrm{M}$. The four tested BCPOs had no toxic effects on the HepG2 cells (Table 2) measured in concentrations up to $1000 \mu \mathrm{M}$ [25] and could therefore be considered as non-hepatotoxic.

Table 2. In vitro toxicity (\% cell viability) of selected $3 \mathbf{A b}, 3 \mathbf{B b}, 3 \mathbf{C b}$ and $3 \mathbf{B a}$ and tacrine in HepG2 cells.

\begin{tabular}{cccccccc}
\hline $\mathbf{B C P O}$ & $\mathbf{1} \mu \mathbf{M}$ & $\mathbf{3 \mu \mathbf { M }}$ & $\mathbf{1 0} \boldsymbol{M} \mathbf{M}$ & $\mathbf{3 0 \mu \mathbf { M }}$ & $\mathbf{1 0 0} \boldsymbol{M} \mathbf{M}$ & $\mathbf{3 0 0} \boldsymbol{\mu} \mathbf{M}$ & $\mathbf{1} \mathbf{m} \mathbf{M}$ \\
\hline $\mathbf{3 A b}$ & $99.3 \pm 4.0$ & $95.3 \pm 2.3$ & $98.5 \pm 2.5$ & $91.5 \pm 4.5$ & $100.8 \pm 3.1$ & $110.5 \pm 5.5$ & $110.4 \pm 4.4$ \\
$\mathbf{3 B b}$ & $107.7 \pm 2.4$ & $111.1 \pm 8.7$ & $104.7 \pm 4.2$ & $104.1 \pm 5.0$ & $111.8 \pm 2.3$ & $118.0 \pm 7.3$ & $127.8 \pm 5.0$ \\
$\mathbf{3 C b}$ & $105.8 \pm 7.0$ & $102.9 \pm 10.8$ & $110.2 \pm 9.1$ & $112.7 \pm 5.8$ & $103.1 \pm 5.7$ & $113.0 \pm 5.2$ & $110.2 \pm 8.0$ \\
$\mathbf{3 B a}$ & $108.6 \pm 2.0$ & $107.7 \pm 4.8$ & $106.2 \pm 3.5$ & $99.2 \pm 4.2$ & $97.0 \pm 5.4$ & $107.6 \pm 2.8$ & $119.5 \pm 6.8$ \\
Tacrine & $105.2 \pm 4.6$ & $103.5 \pm 8.7$ & $97.0 \pm 6.5$ & $93.0 \pm 2.7$ & $95.2 \pm 6.0$ & $47.6 \pm 5.6 * * *$ & $13.9 \pm 0.8 * * *$ \\
\hline
\end{tabular}

Means \pm SEM of triplicates from at least three different cultures. ${ }^{* * *} p<0.001$, as compared to the control cultures (one-way ANOVA). 


\subsection{Blood Brain Barrier Penetration PAMPA Assay}

Prediction of blood-brain barrier (BBB) penetration is summarized in Table 3. Compound $\mathbf{3 A b}$ showed the highest probability to cross the BBB via passive diffusion. Compound 3Ba seems to be also central nervous systems (CNS) available according to the results obtained, however Pe value is on the lower limit for permeable compounds. Compounds $\mathbf{3 B b}$ and $\mathbf{3 C b}$ were not satisfactorily distinguished. Whereas Pe value for the compound $3 \mathrm{Bb}$ fails into the uncertain interval, the value for the compound $3 \mathbf{C b}$ was not determined due to the low solubility of the compound and therefore low $\mathrm{UV} / \mathrm{Vis}$ absorption.

Table 3. Prediction of BBB penetration of drugs expressed as Pe \pm SEM $(n=6-8)$.

\begin{tabular}{|c|c|c|}
\hline \multirow{2}{*}{ Compound } & \multicolumn{2}{|c|}{ BBB Penetration Estimation } \\
\hline & $\mathrm{Pe} \pm \operatorname{SEM}\left(\times 10^{-6} \mathrm{~cm} \mathrm{~s}^{-1}\right)$ & CNS (+l-) \\
\hline $3 \mathrm{Ab}$ & $7.2 \pm 0.6$ & CNS (+) \\
\hline $3 B b$ & $3.6 \pm 0.57$ & $\mathrm{CNS}(+/-)$ \\
\hline $3 \mathrm{Cb}$ & $\mathrm{ND} *$ & \\
\hline 3Ва & $4.6 \pm 0.77$ & CNS (+) \\
\hline Donepezil & $7.3 \pm 0.9$ & CNS (+) \\
\hline Rivastigmine & $6.6 \pm 0.5$ & CNS (+) \\
\hline Tacrine & $5.3 \pm 0.19$ & CNS (+) \\
\hline Testosterone & $11.3 \pm 1.6$ & $\mathrm{CNS}(+)$ \\
\hline Chlorpromazine & $5.6 \pm 0.6$ & CNS (+) \\
\hline Hydrocortisone & $2.85 \pm 0.1$ & $\mathrm{CNS}(+/-)$ \\
\hline Piroxicam & $2.2 \pm 0.15$ & $\mathrm{CNS}(+/-)$ \\
\hline Theophyline & $1.07 \pm 0.18$ & CNS $(-)$ \\
\hline Atenolol & $1.02 \pm 0.37$ & CNS $(-)$ \\
\hline
\end{tabular}

Data obtained for the new compounds correlate well with values for controls drugs, where CNS availability is known and also reported using the PAMPA assay [26,27]. Our data show high resemblance with previously reported results as well as with a general knowledge about the CNS availability for these drugs.

\section{Materials and Methods}

\subsection{Chemistry Methods}

Melting points were determined on a Kofler apparatus (Wagner Munz, München, Germany), and are uncorrected. Progress of the reactions was monitored with TLC using aluminium sheets with silica gel 60 F254 from Merck (Kenilworth, NJ, USA). IR spectra were recorded on a PARAGON FT-IR spectrometer (Perkin-Elmer, Waltham, MA, USA) covering field 400-4000 $\mathrm{cm}^{-1}$. ${ }^{1} \mathrm{H}-\mathrm{NMR}$ and ${ }^{13} \mathrm{C}-\mathrm{NMR}$ were recorded on a Bruker spectrometer (Bruker BioSpin, Fällanden, Switzerland) $\left({ }^{1} \mathrm{H}-\mathrm{NMR}\right.$ at $300 \mathrm{MHz},{ }^{13} \mathrm{C}-\mathrm{NMR}$ at $\left.75 \mathrm{MHz}\right)$ using $\mathrm{CDCl}_{3}$ or DMSO- $d_{6}$ as solvents. The chemical shifts are reported in parts per million (ppm), using tetramethylsilane (TMS) as internal reference. The multiplicities of the signals are indicated by the following abbreviations: s, singlet; $d$, doublet; $\mathrm{t}$, triplet; q, quadruplet; and m, multiplet coupling constants are expressed in Hz. Elemental analysis were performed on Flash EA 1112 Thermo Finnigan, (Thermo scientific, Waltham, MA, USA). The microwave assisted reactions were carried out in synthesis microwave (Anton Paar 300, Peseux, Switzerland) with a maximum power of $300 \mathrm{~W}$.

\subsubsection{General Procedure for the Compounds $\mathbf{1 A}-\mathbf{C}$ and $\mathbf{2 A}-\mathbf{C}$}

A mixture of appropriate aromatic aldehyde $(0.01 \mathrm{~mol})$, ethyl cyanoacetate $(0.01 \mathrm{~mol}), 1$-naphthol (or 2-naphthol) $(0.01 \mathrm{~mol})$ in ethanol $(20 \mathrm{~mL})$ in the presence of piperidine $(0.2$ equiv) was irradiated 
for $10 \mathrm{~min}$ in a sealed tube. The irradiation was programed to maintain a constant temperature $\left(80{ }^{\circ} \mathrm{C}, 150 \mathrm{~W}\right)$. The obtained precipitate was filtered, washed with cold ethanol and dried, to give the desired compounds.

Ethyl 3-amino-1-phenyl-1H-benzo[f]chromene-2-carboxylate (1A) [27]: Yield 90\%; mp 168-170 ${ }^{\circ} \mathrm{C} ; \mathrm{IR}(\mathrm{KBr})$ $v_{\max } 3300-3438,1685 \mathrm{~cm}^{-1} ;{ }^{1} \mathrm{H}-\mathrm{NMR}\left(\mathrm{DMSO}-d_{6}\right) 1.23-1.28(\mathrm{~m}, 3 \mathrm{H}), 4.08-4.17(\mathrm{~m}, 2 \mathrm{H}), 5.51(\mathrm{~s}, 1 \mathrm{H})$, 7.00-8.02 (m, 11H, arom.), 7.67 (s, 2H, NH $)$; ${ }^{13} \mathrm{C}-\mathrm{NMR}$ (DMSO-d 6 ) 14.9, 37.0, 59.3, 78.2, 117.2, 119.3, $123.6,125.2,126.4,127.5,128.2,128.5,129.0,129.4,130.7,131.2,147.2,147.3,160.9,168.6$.

Ethyl 3-amino-1-(3-methoxyphenyl)-1H-benzo[f]chromene-2-carboxylate (1B): Yield 73\%; mp $168-170{ }^{\circ} \mathrm{C}$; IR (KBr) $v_{\max } 3339-3425,1690 \mathrm{~cm}^{-1} ;{ }^{1} \mathrm{H}-\mathrm{NMR}$ (DMSO-d $)$ 1.14-1.20 (m, 3H), $3.80(\mathrm{~s}, 3 \mathrm{H}), 4.01-4.12$ $(\mathrm{m}, 2 \mathrm{H}), 5.82(\mathrm{~s}, 1 \mathrm{H}), 6.72-8.25\left(\mathrm{~m}, 10 \mathrm{H}\right.$, arom.), $7.68\left(\mathrm{~s}, 2 \mathrm{H}, \mathrm{NH}_{2}\right) ;{ }^{13} \mathrm{C}-\mathrm{NMR}$ (DMSO-d 6$)$ 14.7, 31.3, 55.8, 59.1, 77.5, 111.6,117.1, 119.5, 120.8, 123.7, 125.0, 127.3, 127.7, 128.9, 128.9, 130.5, 131.0, 131.3, 135.5, 147.3, $156.1,161.4,169.0$.

Ethyl 3-amino-1-p-methylphenyl-1H-benzo[f]chromene-2-carboxylate (1C) [28]: Yield 75\%; mp 194-196 ${ }^{\circ}$; IR (KBr) $v_{\max } 3320-3440\left(\mathrm{NH}_{2}\right), 1687(\mathrm{CO}) \mathrm{cm}^{-1} ;{ }^{1} \mathrm{H}-\mathrm{NMR}$ (DMSO-d $\left.{ }_{6}\right) 1.24-1.31(\mathrm{~m}, 3 \mathrm{H}), 2.10(\mathrm{~s}, 3 \mathrm{H})$, 4.09-4.23 (m, 2H), 5.49 (s, 1H), 6.93-8.01 (m, 10H, arom.), 7.68 (s, 2H, NH $)$; ${ }^{13}$ C-NMR (DMSO-d 6$) 14.9$, 20.9, 36.6, 59.3, 78.3, 117.1, 119.4, 123.6, 125.2, 127.4, 128.0, 129.0, 129.1, 129.3, 130.8, 131.2, 135.3, 144.4, $147.2,160.9,168.7$.

Ethyl 2-amino-4-phenyl-4H-benzo[h]chromene-3-carboxylate (2A) [29]: Yield 88\%; mp 160-162 ${ }^{\circ} \mathrm{C}$; IR (KBr) $v_{\max } 3372-3260,1692 \mathrm{~cm}^{-1} ;{ }^{1} \mathrm{H}-\mathrm{NMR}\left(\mathrm{DMSO}-d_{6}\right) 1.10-1.18(\mathrm{~m}, 3 \mathrm{H}), 4.01-4.11(\mathrm{~m}, 2 \mathrm{H}), 5.04(\mathrm{~s}, 1 \mathrm{H})$, 7.04-8.33 (m, 11H, arom.), $7.64\left(\mathrm{~s}, 2 \mathrm{H}, \mathrm{NH}_{2}\right) ;{ }^{13} \mathrm{C}-\mathrm{NMR}$ (DMSO-d 6 ) 14.7, 40.5, 59.0, 76.8, 121.1, 121.4, $123.2,124.1,126.4,126.9,126.9,127.0,127.7,128.1,128.6,132.9,143.2,148.2,161.2,168.7$.

Ethyl 2-amino-4-m-methoxyphényl-4H-benzo[h] chromene-3-carboxylate (2B): Yield 75\%; mp 156-158 ${ }^{\circ} \mathrm{C}$; IR (KBr) $v_{\max } 3393-3280,1663 \mathrm{~cm}^{-1} ;{ }^{1} \mathrm{H}-\mathrm{NMR}$ (DMSO-d $)$ 1.09-1.18 (m, 3H), $3.68(\mathrm{~s}, 3 \mathrm{H}), 4.02-4.14$ $(\mathrm{m}, 2 \mathrm{H}), 5.01(\mathrm{~s}, 1 \mathrm{H}), 6.67-8.32\left(\mathrm{~m}, 10 \mathrm{H}\right.$, arom.) $7.63\left(\mathrm{~s}, 2 \mathrm{H}, \mathrm{NH}_{2}\right) ;{ }^{13} \mathrm{C}-\mathrm{NMR}$ (DMSO- $\left.d_{6}\right) 14.2,40.0$, $54.8,58.6,76.2,110.7,113.5,119.5,120.6,120.8,122.7,123.6,126.4,126.4,126.5,127.6,129.2,132.4,142.8$, $149.3,159.0,160.8,168.2$.

Ethyl-2-amino-4-p-methylphenyl-4H-benzo[h]chromene-3-carboxylate (2C) [29]: Yield 68\%; mp 158-160 ${ }^{\circ} \mathrm{C}$; IR (KBr) $v_{\max } 3315-3452,1672 \mathrm{~cm}^{-1} ;{ }^{1} \mathrm{H}-\mathrm{NMR}$ (DMSO-d $)$ 1.10-1.17 (m, 3H), $2.28(\mathrm{~s}, 3 \mathrm{H}), 4.00-4.09$ $(\mathrm{m}, 2 \mathrm{H}), 4.98(\mathrm{~s}, 1 \mathrm{H}), 6.98-8.29\left(\mathrm{~m}, 10 \mathrm{H}\right.$, arom.), $7.62\left(\mathrm{~s}, 2 \mathrm{H}, \mathrm{NH}_{2}\right) ;{ }^{13} \mathrm{C}-\mathrm{NMR}\left(\mathrm{DMSO}-d_{6}\right) 14.7,20.9$, $40.8,59.0,76.9,121.2,121.8,123.3,124.1,126.8,126.9,127.0,127.6,128.0,129.2,132.9,135.4,143.2,145.3$, $161.2,168.7$.

\subsubsection{General Procedure for the Synthesis of Benzochromenopyrimidinones (BCPOs)}

$\mathrm{POCl}_{3}(0.14 \mathrm{~mL}, 0.23 \mathrm{~g}, 1.5$ equiv) was added dropwise to a mixture of the corresponding ethyl aminobenzochromene-2-carboxylate and the appropriate lactam (1.5 equiv) in 1,2-dichloroethane $(20 \mathrm{~mL})$. After microwave irradiation, approximately $80 \%$ of the solvent was evaporated and water $(10 \mathrm{~mL})$ was added. The solution was basified with $20 \%$ aqueous $\mathrm{NaOH}$, then the mixture was extracted with $\mathrm{CH}_{2} \mathrm{Cl}_{2}$, washed with water $(20 \mathrm{~mL})$, and dried over $\mathrm{MgSO}_{4}$. The solvent was evaporated, the solid obtained was washed with ether and filtered to give benzochromenopyrimidinones 3 and 4 .

14-Phenyl-10,11-dihydro-14H-benzo[5,6]chromeno[2,3-d]pyrrolo[1,2-a]pyrimidin-13(9H)-one (3Aa): Yield $80 \% ; \mathrm{mp}>260{ }^{\circ} \mathrm{C}$; IR (KBr) $v_{\max } 1667,1587 \mathrm{~cm}^{-1} ;{ }^{1} \mathrm{H}-\mathrm{NMR}\left(\mathrm{CDCl}_{3}\right) 2.18-2.22$ (m, 2H, H10), $2.28-2.36$ (m, 2H, H9), 3.20-3.29 (m, 2H, H11), 5.31 (s, 1H, H14), 6.64 (d, J = 7.8 Hz 1H, H6), 7.19-7.48 (m, 7H, $\left.\mathrm{H} 2, \mathrm{H} 3, \mathrm{H}^{\prime}{ }^{\prime}, \mathrm{H}^{\prime}, \mathrm{H}^{\prime}{ }^{\prime}, \mathrm{H}^{\prime}{ }^{\prime}, \mathrm{H}^{\prime}{ }^{\prime}\right), 7.80$ (d, $\left.\mathrm{J}=8.1 \mathrm{~Hz}, 2 \mathrm{H}, \mathrm{H} 4, \mathrm{H} 5\right), 7.96$ (d, J = 8.4 Hz,1H,H1); ${ }^{13} \mathrm{C}-\mathrm{NMR}$ $\left(\mathrm{CDCl}_{3}\right) 18.6\left(\mathrm{CH}_{2}, \mathrm{C} 10\right), 32.0\left(\mathrm{CH}_{2}, \mathrm{C} 9\right), 36.0(\mathrm{CH}, \mathrm{C} 14), 46.6(\mathrm{CH}, \mathrm{C} 11), 100.8(\mathrm{C}, \mathrm{C} 13 \mathrm{a}), 115.9(\mathrm{CH}$, C6), $116.9(\mathrm{CH}, \mathrm{C} 1), 123.1(\mathrm{CH}, \mathrm{C} 3), 124.4(\mathrm{CH}, \mathrm{C} 2), 126.1(\mathrm{CH}, \mathrm{C} 4), 126.3(\mathrm{CH}, \mathrm{C} 5), 126.6\left(\mathrm{CH}_{1} \mathrm{C}^{\prime}\right)$, 127.8 (2 CH, C2' $\left.{ }^{\prime} \mathrm{C}^{\prime}\right), 127.9$ (2 CH, C3 $\left.{ }^{\prime}, \mathrm{C}^{\prime}\right), 128.8(\mathrm{C}, \mathrm{C} 14 \mathrm{~b}), 130.6$ (C, C14a), $131.0(\mathrm{C}, \mathrm{C} 4 \mathrm{a}), 143.3$ 
(C, C1'), 147.8 (C, C6a), 160.5 (C, C8a), 160.9 (C, C7a), 162.1 (C, C13). Anal. Calcd. for $\mathrm{C}_{24} \mathrm{H}_{18} \mathrm{~N}_{2} \mathrm{O}_{2}$ : C, 78.67; H, 4.95; N, 7.65. Found: C, 78.61; H, 4.98; N, 7.69.

15-Phenyl-10,11,12,15-tetrahydro-9H-benzo[5,6]chromeno[2,3-d]pyrido[1,2-a]pyrimidin-14-one (3Ab): Yield 96\%; mp $236{ }^{\circ} \mathrm{C}$; IR (KBr) $v_{\max } 1669,1587 \mathrm{~cm}^{-1} ;{ }^{1} \mathrm{H}-\mathrm{NMR}\left(\mathrm{CDCl}_{3}\right)$ 1.83-1.94 (m, 4H, H11, H10), 2.91-2.94 (m,H9, 2H), 3.87-3.93 (m, H12, 2H), 5.76 (s, H15, 1H), 7.07 (d, J = 7.8 Hz, H6, 1H), 7.16-7.52 (m, H2, H3, H5, $\left.\mathrm{H} 2^{\prime}, \mathrm{H}^{\prime}{ }^{\prime}, \mathrm{H}^{\prime}{ }^{\prime}, \mathrm{H}^{\prime}, \mathrm{H}^{\prime}{ }^{\prime}, 8 \mathrm{H}\right), 7.97 \mathrm{~d}(\mathrm{~J}=8.4 \mathrm{~Hz}, \mathrm{H} 1, \mathrm{H} 4,2 \mathrm{H}) ;{ }^{13} \mathrm{C}-\mathrm{NMR}\left(\mathrm{CDCl}_{3}\right) 18.2$ ( $\left.\mathrm{CH}_{2}, \mathrm{C} 10\right), 20.9\left(\mathrm{CH}_{2}, \mathrm{C} 11\right), 30.9\left(\mathrm{CH}_{2}, \mathrm{C} 9\right), 35.9(\mathrm{CH}, \mathrm{C} 15), 42.4(\mathrm{CH}, \mathrm{C} 12), 99.6(\mathrm{CH}, \mathrm{C} 14 \mathrm{a}), 116.4$ (C, C6), $\left.117.3(\mathrm{CH}, \mathrm{C} 1), 123.3(\mathrm{CH}, \mathrm{C} 3), 124.9(\mathrm{CH}, \mathrm{C} 2), 126.4(\mathrm{CH}, \mathrm{C} 4), 127.1(\mathrm{CH}, \mathrm{C} 5), 128.1(\mathrm{CH}, \mathrm{C4})^{\prime}\right)$, 128.2 (2 CH, C2', C6'), 128.5 (2 CH, C3' $\left.{ }^{\prime} \mathrm{C5}^{\prime}\right), 129.4$ (C, C15b), 130.4 (C, C15a), 130.9 (C, C4a), 144.2 (C, C1'), 147.7 (C, C6a), 158.9 (C, C8a), 159.4 (C, C7a), 161.4 (C,C14). Anal. Calcd. for $\mathrm{C}_{25} \mathrm{H}_{20} \mathrm{~N}_{2} \mathrm{O}_{2}$ : C, 78.93; H, 5.30; N, 7.36. Found: C, 78.92; H, 5.32; N, 7.32.

16-Phenyl-10,11,12,13,-tetrahydro-16H-benzo[5,6]chromeno[2' ,3' $^{\prime}$ 4,5]pyrimido[1,2-a]azepin-15(9H)-one (3Ac): Yield 85\%; mp $242{ }^{\circ} \mathrm{C}$; IR (KBr) $v_{\max } 1660,1589 \mathrm{~cm}^{-1}$; ${ }^{1} \mathrm{H}-\mathrm{NMR}\left(\mathrm{CDCl}_{3}\right) 1.78-1.83(\mathrm{~m}, \mathrm{H} 12, \mathrm{H} 11, \mathrm{H} 10$, $\mathrm{H} 9,8 \mathrm{H}), 2.97-2.99$ (m, H13, 2H), $5.89(\mathrm{~s}, \mathrm{H} 16,1 \mathrm{H}), 7.09 \mathrm{~d}(\mathrm{~J}=7.8 \mathrm{~Hz}, \mathrm{H6}, 1 \mathrm{H}), 7.19-7.48 \mathrm{~m}(\mathrm{~m}, \mathrm{H} 2$, $\left.\mathrm{H} 3, \mathrm{H}^{\prime}, \mathrm{H}^{\prime}, \mathrm{H}^{\prime}, \mathrm{H6}^{\prime}, \mathrm{H} 4,7 \mathrm{H}\right), 7.81(\mathrm{~d}, J=8.1 \mathrm{~Hz}, \mathrm{H} 4, \mathrm{H} 5,2 \mathrm{H}), 7.96(\mathrm{~d}, J=8.4 \mathrm{~Hz}, \mathrm{H} 1,1 \mathrm{H}) ;{ }^{13} \mathrm{C}-\mathrm{NMR}$ $\left(\mathrm{CDCl}_{3}\right) 24.0\left(\mathrm{CH}_{2}, \mathrm{C} 10\right), 26.7\left(\mathrm{CH}_{2}, \mathrm{C11}\right), 29.1\left(\mathrm{CH}_{2}, \mathrm{C} 12\right), 36.4\left(\mathrm{CH}_{2}, \mathrm{C} 16\right), 36.8(\mathrm{CH}, \mathrm{C} 9), 42.6(\mathrm{CH}, \mathrm{C} 13)$, 100.6 (CH,C15a), 116.2 (C,C6), $117.0(\mathrm{CH}, \mathrm{C} 1), 123.2(\mathrm{CH}, \mathrm{C} 3), 124.3(\mathrm{CH}, \mathrm{C} 2), 126.0(\mathrm{CH}, \mathrm{C} 4), 126.5$ (CH, C5), $127.9\left(2 \mathrm{CH}, \mathrm{C2}^{\prime}, \mathrm{C6}^{\prime}\right), 128.0\left(2 \mathrm{CH}, \mathrm{C}^{\prime}, \mathrm{C}^{\prime}\right), 128.4\left(\mathrm{CH}, \mathrm{C4}^{\prime}\right), 128.7(\mathrm{C}, \mathrm{C} 16 \mathrm{~b}), 130.6$ (C, C16a), 130.9 (C, C4a), 143.4 (C, C1'), 147.7 (C, C6a), 158.8 (C, C8a), 161.6 (C, C7a), 162.5 (C, C15). Anal. Calcd. for $\mathrm{C}_{26} \mathrm{H}_{22} \mathrm{~N}_{2} \mathrm{O}_{2}$ : C, 79.17; H, 5.62; N, 7.10. Found: C, 79.25; H, 5.60; N, 7.17.

14-(3'Methoxyphenyl)-10,11-dihydro-14H-benzo[5,6]chromeno[2,3-d]pyrrolo[1,2-a]pyrimidin-13(9H)-one (3Ba): Yield 81\%; mp $211{ }^{\circ} \mathrm{C}$; IR (KBr) $v_{\max } 1660,1591 \mathrm{~cm}^{-1}$; ${ }^{1} \mathrm{H}-\mathrm{NMR}\left(\mathrm{CDCl}_{3}\right) 2.22-2.27(\mathrm{~m}, \mathrm{H} 10,2 \mathrm{H})$, 3.01-3.14 (m, H9, 2H), $3.71\left(\mathrm{~s}, \mathrm{OCH}_{3}, 3 \mathrm{H}\right), 4.13-4.17(\mathrm{~m}, \mathrm{H} 11,2 \mathrm{H}), 5.92(\mathrm{~s}, \mathrm{H} 14,1 \mathrm{H}), 6.66(\mathrm{~d}, J=7.8 \mathrm{~Hz}$, $\mathrm{H6}, 1 \mathrm{H}), 6.99-7.48$ (m, H2, H3, H2' $\left.{ }^{\prime} \mathrm{H}^{\prime}, \mathrm{H6}^{\prime}, \mathrm{H} 4^{\prime}, 6 \mathrm{H}\right), 7.82$ (d, J = 8.4 Hz, H4, H5, 2H), 7.99 (d, $J=8.1 \mathrm{~Hz}, \mathrm{H1}, 1 \mathrm{H}) ;{ }^{13} \mathrm{C}-\mathrm{NMR}\left(\mathrm{CDCl}_{3}\right) 18.6(\mathrm{CH}, \mathrm{C} 10), 31.9(\mathrm{CH}, \mathrm{C} 9), 35.9(\mathrm{CH}, \mathrm{C} 14), 46.5(\mathrm{CH}, \mathrm{C} 11)$, $55.0\left(\mathrm{OCH}_{3}\right), 100.7(\mathrm{C}, \mathrm{C} 13 \mathrm{a}), 111.3\left(\mathrm{CH}, \mathrm{C} 4^{\prime}\right), 114.0\left(\mathrm{CH}, \mathrm{C} 2^{\prime}\right), 115.9(\mathrm{CH}, \mathrm{C} 5), 116.9\left(\mathrm{CH}, \mathrm{C6}^{\prime}\right), 120.4$ (C, C14a), 123.1 (CH, C1), $124.4(\mathrm{CH}, \mathrm{C} 3), 126.5$ (CH, C2), 127.9 (CH, C6), 128.7 (CH, C4), 128.8 (C, C4a), 130.6 (CH, C5'), 131.0 (C, C14b), 144.9 (C, C1'), 147.8 (C, C6a), 158.1 (C, C8a), 160.6 (C, C7a), 161.0 (C, C13), $162.0\left(\mathrm{C}, \mathrm{C}^{\prime}\right)$. Anal. Calcd. for $\mathrm{C}_{25} \mathrm{H}_{20} \mathrm{~N}_{2} \mathrm{O}_{3}$ : C, 75.74; $\mathrm{H}, 5.09 ; \mathrm{N}, 7.07$. Found: $\mathrm{C}, 75.69$; $\mathrm{H}, 5.12 ; \mathrm{N}, 7.11$.

15-(3'-Methoxyphenyl)-10,11,12,15-tetrahydro-9H-benzo[5,6]chromeno[2,3-d]pyrido[1,2-a]pyrimidin-14-one (3Bb): Yield 90\%; mp $212{ }^{\circ} \mathrm{C}$; IR (KBr) $v_{\max } 1658,1583 \mathrm{~cm}^{-1} ;{ }^{1} \mathrm{H}-\mathrm{NMR}\left(\mathrm{CDCl}_{3}\right)$ 1.85-1.94 (m, H9, H10, $\mathrm{H} 11,6 \mathrm{H}), 2.86-2.94(\mathrm{~m}, \mathrm{H} 12,2 \mathrm{H}), 3.71\left(\mathrm{~s}, \mathrm{OCH}_{3}, 3 \mathrm{H}\right), 5.89(\mathrm{~s}, \mathrm{H} 15,1 \mathrm{H}), 6.65(\mathrm{~d}, J=7.8 \mathrm{~Hz}, \mathrm{H} 6,1 \mathrm{H})$, 6.99-7.46 (m, H2, H3, H2' $\left.\mathrm{H}^{\prime}, \mathrm{H}^{\prime}{ }^{\prime}, \mathrm{H} 4^{\prime}, 6 \mathrm{H}\right), 7.80$ (d, J = 8.4 Hz, H4, H5, 2H), 7.98 (d, J = 8.1 Hz,H1, 1H); ${ }^{13} \mathrm{C}-\mathrm{NMR}\left(\mathrm{CDCl}_{3}\right) 19.0(\mathrm{CH}, \mathrm{C} 10), 21.8(\mathrm{CH}, \mathrm{C} 11), 31.5(\mathrm{CH}, \mathrm{C} 9), 36.6(\mathrm{CH}, \mathrm{C} 15), 42.9(\mathrm{CH}, \mathrm{C} 12)$, $55.0\left(\mathrm{C}, \mathrm{OCH}_{3}\right), 100.8(\mathrm{C}, \mathrm{C} 14 \mathrm{a}), 114.6\left(\mathrm{CH}, \mathrm{C}^{\prime}\right), 116.6(\mathrm{CH}, \mathrm{C} 5), 117.1\left(\mathrm{CH}, \mathrm{C}^{\prime}\right), 117.5\left(\mathrm{CH}, \mathrm{C}^{\prime}\right)$, 121.0 (C, C15a), 123.7 (CH, C1), 124.8 (CH, C3), 127.0 (CH, C2), $128.4(\mathrm{CH}, \mathrm{C} 6), 129.1(\mathrm{CH}, \mathrm{C} 4), 129.3$ (C, C4a), 131.0 (C, C15b), $131.2\left(\mathrm{CH}, \mathrm{C}^{\prime}\right), 145.5$ (C, C1'), 148.2 (C, C6a), 158.5 (C,C8a), 159.0 (C, C7a), 159.5 (C, C14), $162.4\left(\mathrm{C}, \mathrm{C}^{\prime}\right)$. Anal. Calcd. or $\mathrm{C}_{26} \mathrm{H}_{22} \mathrm{~N}_{2} \mathrm{O}_{3}$ : C, 76.08; $\mathrm{H}, 5.40 ; \mathrm{N}, 6.82$. Found: $\mathrm{C}, 76.13$; $\mathrm{H}, 5.36 ; \mathrm{N}, 6.85$.

16-(3'-Methoxyphenyl)-10,11,12,13-tetrahydro-16H-benzo[5,6]chromeno[ $\left.2^{\prime}, 3^{\prime}, 4,5\right]$ pyrimido[1,2-a]azepin15(9H)-one (3Bc): Yield 82\%; $\mathrm{mp} 206^{\circ} \mathrm{C}$; IR (KBr) $v_{\max } 1662,1585 \mathrm{~cm}^{-1} ;{ }^{1} \mathrm{H}-\mathrm{NMR}\left(\mathrm{CDCl}_{3}\right) 1.79-2.33$ (m, H9, H10, H11, H12, H8), 2.92-2.99 (m, H13, 2H), 3.71 (s, $\left.\mathrm{OCH}_{3}, 3 \mathrm{H}\right), 5.87$ (s, H16, 1H), 6.65 (d, $J=7.8 \mathrm{~Hz}, \mathrm{H} 6,1 \mathrm{H}), 6.84-7.49\left(\mathrm{~m}, \mathrm{H} 2, \mathrm{H} 3, \mathrm{H}^{\prime}{ }^{\prime} \mathrm{H}^{\prime}, \mathrm{H}^{\prime}, \mathrm{H} 4^{\prime}, 6 \mathrm{H}\right), 7.80(\mathrm{~d}, J=8.4 \mathrm{~Hz}, \mathrm{H} 4, \mathrm{H} 5,2 \mathrm{H})$, $7.98(\mathrm{~d}, J=8.1 \mathrm{~Hz}, \mathrm{H1}, 1 \mathrm{H}) ;{ }^{13} \mathrm{C}-\mathrm{NMR}\left(\mathrm{CDCl}_{3}\right) 24.5(\mathrm{CH}, \mathrm{C} 10), 27.2(\mathrm{CH}, \mathrm{C} 11), 29.7(\mathrm{CH}, \mathrm{C} 12), 36.9$ $(\mathrm{CH}, \mathrm{C} 16), 37.4(\mathrm{CH}, \mathrm{C} 9), 43.2(\mathrm{CH}, \mathrm{C} 13), 55.0\left(\mathrm{OCH}_{3}\right), 101.0(\mathrm{C}, \mathrm{C} 15 \mathrm{a}), 111.6\left(\mathrm{C}, \mathrm{C} 4^{\prime}\right), 114.6\left(\mathrm{CH}, \mathrm{C2}{ }^{\prime}\right)$, $116.6(\mathrm{CH}, \mathrm{C} 5), 117.5\left(\mathrm{CH}, \mathrm{C6}^{\prime}\right), 121.1(\mathrm{C}, \mathrm{C} 16 \mathrm{a}), 123.7(\mathrm{CH}, \mathrm{C} 1), 124.9(\mathrm{CH}, \mathrm{C} 3), 127.0(\mathrm{CH}, \mathrm{C} 2), 128.4$ (CH, C6), 129.2 (CH, C4), 129.3 (C, C4a), 131.1 (CH, C5'), 131.4 (C, C16b), $145.4\left(\mathrm{C}, \mathrm{C1}^{\prime}\right), 148.1$ (C, C6a), 
159.3 (C, C8a), 159.5 (C, C7a), 162.1 (C, C15), 163.5 (C, C3'). Anal. Calcd. for $\mathrm{C}_{27} \mathrm{H}_{24} \mathrm{~N}_{2} \mathrm{O}_{3}$ : C, 76.40 ; $H, 5.70 ; N, 6.60$. Found: $C, 76.36 ; H, 5.73 ; N, 6.64$.

14-(4'-Methylphenyl)-10,11-dihydro-14H-benzo[5,6]chromeno[2,3-d]pyrrolo[1,2-a]pyrimidin-13(9H)-one (3Ca): Yield 82\%; mp > $260{ }^{\circ} \mathrm{C}$; IR $(\mathrm{KBr}) v_{\max } 1661,1594 \mathrm{~cm}^{-1} ;{ }^{1} \mathrm{H}-\mathrm{NMR}\left(\mathrm{CDCl}_{3}\right)$ 1.21-1.25 (m, $\mathrm{H} 10,2 \mathrm{H}), 2.2\left(\mathrm{~s}, \mathrm{CH}_{3}, 3 \mathrm{H}\right), 3.06-3.12(\mathrm{~m}, \mathrm{H} 9,2 \mathrm{H}), 4.05-4.11(\mathrm{~m}, \mathrm{H} 11,2 \mathrm{H}), 5.90(\mathrm{~s}, \mathrm{H} 14,1 \mathrm{H}), 7.05$ (d, $\left.J=8.7 \mathrm{~Hz}, \mathrm{H}^{\prime}{ }^{\prime}, \mathrm{H}^{\prime}, 2 \mathrm{H}\right), 7.28-7.47(\mathrm{~m}, \mathrm{H} 2, \mathrm{H} 3, \mathrm{H} 4, \mathrm{H} 5, \mathrm{H} 6,5 \mathrm{H}), 7.81\left(\mathrm{~d}, J=8.7 \mathrm{~Hz}, \mathrm{H2}{ }^{\prime}, \mathrm{H6}^{\prime}, 2 \mathrm{H}\right), 7.97$ $\mathrm{d}(\mathrm{d}, J=8.1 \mathrm{~Hz}, \mathrm{H1}, 1 \mathrm{H}),{ }^{13} \mathrm{C}-\mathrm{NMR}\left(\mathrm{CDCl}_{3}\right) 19.1\left(\mathrm{CH}_{2}, \mathrm{C} 10\right), 20.9\left(\mathrm{CH}_{3}\right), 32.4(\mathrm{CH}, \mathrm{C} 9), 36.0(\mathrm{CH}, \mathrm{C} 14)$, 47.0 (CH, C11), 101.5 (C, C13a), 116.7 (CH, C6), $117.5(\mathrm{CH}, \mathrm{C} 1), 123.7(\mathrm{CH}, \mathrm{C} 3), 124.8(\mathrm{CH}, \mathrm{C} 2), 127.0$ (CH, C4), $128.3(\mathrm{CH}, \mathrm{C} 5), 128.4\left(2 \mathrm{CH}, \mathrm{C2}^{\prime}, \mathrm{C}^{\prime}\right), 129.0\left(2 \mathrm{CH}, \mathrm{C}^{\prime}, \mathrm{C}^{\prime}\right), 129.2$ (C, C14b), 131.1 (C, C14a), 131.5 (C, C4a), 136.2 (C, C4'), 141.0 (C, C1'), 148.2 (C, C6a), 161.1 (C, C8a), 161.4 (C, C7a), 162.4 (C, C13). Anal. Calcd. for $\mathrm{C}_{25} \mathrm{H}_{20} \mathrm{~N}_{2} \mathrm{O}_{2}$ : C, 78.93; H, 5.30; N, 7.36. Found: $\mathrm{C}, 78.97 ; \mathrm{H}, 5.27 ; \mathrm{N}, 7.33$.

15-(4'-Methylphenyl)-10,11,12,15-tetrahydro-9H-benzo[5,6]chromeno[2,3-d]pyrido[1,2-a]pyrimidin-14-one (3Cb): Yield 94\%; mp > $260{ }^{\circ} \mathrm{C}$; IR (KBr) $v_{\max } 1658,1586 \mathrm{~cm}^{-1} ;{ }^{1} \mathrm{H}-\mathrm{NMR}\left(\mathrm{CDCl}_{3}\right) 1.83-1.88$ (m, H10, 2H), 1.90-1.95 (m, H11, 2H), 2.22 (s, $\left.\mathrm{CH}_{3}, 3 \mathrm{H}\right), 2.92-2.96$ (m, H9, 2H), 3.90-3.97 (m, H12, 2H), $5.86(\mathrm{~s}, \mathrm{H} 15,1 \mathrm{H}), 7.03\left(\mathrm{~d}, J=7.6 \mathrm{~Hz}, \mathrm{H3}^{\prime}, \mathrm{H}^{\prime}, 2 \mathrm{H}\right), 7.28-7.48(\mathrm{~m}, \mathrm{H} 2, \mathrm{H} 3, \mathrm{H} 4, \mathrm{H} 5, \mathrm{H} 6,5 \mathrm{H}), 7.81$ $\left(\mathrm{d}, J=8.1 \mathrm{~Hz}, \mathrm{H2}{ }^{\prime}, \mathrm{Hb}^{\prime}, 2 \mathrm{H}\right), 7.96(\mathrm{~d}, J=8.4 \mathrm{~Hz}, \mathrm{H1}, 1 \mathrm{H}) ;{ }^{13} \mathrm{C}-\mathrm{NMR}\left(\mathrm{CDCl}_{3}\right) 19.0\left(\mathrm{CH}_{2}, \mathrm{C} 10\right), 21.0$ $\left(\mathrm{CH}_{3}\right), 21.7(\mathrm{CH}, \mathrm{C} 11), 31.4(\mathrm{CH}, \mathrm{C} 9), 36.2(\mathrm{CH}, \mathrm{C} 15), 43.0(\mathrm{CH}, \mathrm{C} 12), 101.1(\mathrm{C}, \mathrm{C} 14 \mathrm{a}), 116.7(\mathrm{CH}, \mathrm{C} 6)$, $117.5(\mathrm{CH}, \mathrm{C} 1), 123.7(\mathrm{CH}, \mathrm{C} 3), 124.9(\mathrm{CH}, \mathrm{C} 2), 127.1(\mathrm{CH}, \mathrm{C} 4), 128.4(\mathrm{CH}, \mathrm{C} 5), 128.9\left(2 \mathrm{CH}, \mathrm{C2}^{\prime}, \mathrm{C}^{\prime}\right)$, 129.1 (2CH, C3', C5'), 129.2 (C, C15b), 131.1 (C, C15a), 131.4 (C, C4a), 136.2 (C, C4'), 141.0 (C, C1'), 148.1 (C, C6a), 158.5 (C, C8a), 159.0 (C, C7a), 162.3 (C, C14). Anal. Calcd. for $\mathrm{C}_{26} \mathrm{H}_{22} \mathrm{~N}_{2} \mathrm{O}_{2}$ : C, 79.17; $\mathrm{H}, 5.62 ; \mathrm{N}, 7.10$. Found: C, 79.12; H, 5.65; N, 7.14.

16-(4'-Methylphenyl)-10,11,12,13-tetrahydro-16H-benzo[5,6]chromeno[2',3' 4 ,5]pyrimido[1,2-a]azepin-15(9H)-one (3Cc): Yield 86\%; $\mathrm{mp}>260^{\circ} \mathrm{C}$; IR (KBr) $v_{\max } 1659,1589 \mathrm{~cm}^{-1} ;{ }^{1} \mathrm{H}-\mathrm{NMR}\left(\mathrm{CDCl}_{3}\right)$ 1.82-2.04 (m, H9, $\mathrm{H} 10, \mathrm{H} 11, \mathrm{H} 12,8 \mathrm{H}), 2.22\left(\mathrm{~s}, 3 \mathrm{H}, \mathrm{CH}_{3}, 3 \mathrm{H}\right), 4.05-4.11(\mathrm{~m}, \mathrm{H} 13,2 \mathrm{H}), 5.86(\mathrm{~s}, \mathrm{H} 16,1 \mathrm{H}), 7.03(\mathrm{~d}, J=8.7 \mathrm{~Hz}$, $\left.\mathrm{H}^{\prime}, \mathrm{H}^{\prime}, 2 \mathrm{H}\right), 7.28-7.48(\mathrm{~m}, \mathrm{H} 2, \mathrm{H} 3, \mathrm{H} 4, \mathrm{H} 5, \mathrm{H} 6,5 \mathrm{H}), 7.80$ (d, $\left.J=9 \mathrm{~Hz}, \mathrm{H}^{\prime}, \mathrm{H6}^{\prime}, 2 \mathrm{H}\right), 7.98$ (d, J = $8.4 \mathrm{~Hz}$, $\mathrm{H} 1,1 \mathrm{H}) ;{ }^{13} \mathrm{C}-\mathrm{NMR}\left(\mathrm{CDCl}_{3}\right) 21.0(\mathrm{CH}, \mathrm{C} 11), 24.5\left(\mathrm{CH}_{3}\right), 27.2\left(\mathrm{CH}_{2}, \mathrm{C} 10\right), 29.6(\mathrm{CH}, \mathrm{C} 12), 36.5(\mathrm{CH}, \mathrm{C} 9)$, 37.3 (CH, C16), 43.1 (CH, C13), 101.3 (C, C15a), $116.9(\mathrm{CH}, \mathrm{C} 6), 117.5$ (CH, C1), $123.0(\mathrm{CH}, \mathrm{C} 3), 123.7$ ( $\mathrm{CH}, \mathrm{C} 2), 124.8(\mathrm{CH}, \mathrm{C} 4), 127.0(\mathrm{CH}, \mathrm{C} 5), 128.4\left(2 \mathrm{CH}, \mathrm{C2}^{\prime}, \mathrm{C}^{\prime}\right), 129.0\left(2 \mathrm{CH}, \mathrm{C}^{\prime}, \mathrm{C}^{\prime}\right), 129.1(\mathrm{C}, \mathrm{C} 16 \mathrm{~b})$, 131.1 (C, C16a), 131.5 (C, C4a), 136.1 (C, C4'), 141.0 (C, C1'), 148.1 (C, C6a), 159.3 (C, C8a), 162.1 (C, C7a), 163.3 (C, C15). Anal. Calcd. for $\mathrm{C}_{27} \mathrm{H}_{24} \mathrm{~N}_{2} \mathrm{O}_{2}$ : C, 79.39; H, 5.92; N, 6.86. Found: C, 79.41; $\mathrm{H}, 5.90 ; \mathrm{N}, 6.89$.

7-Phenyl-11,12-dihydro-7H-benzo[7,8]chromeno[2,3-d]pyrrolo[1,2-a]pyrimidin-8(10H)-one (4Aa): Yield 79\%; $\mathrm{mp}>260{ }^{\circ} \mathrm{C}$; IR (KBr) $v_{\max } 1666,1577 \mathrm{~cm}^{-1} ;{ }^{1} \mathrm{H}-\mathrm{NMR}\left(\mathrm{CDCl}_{3}\right) 2.41-2.51(\mathrm{~m}, 2 \mathrm{H}, \mathrm{H} 11), 3.07-3.17$ (m, H12, 2H), 3.71-3.94 (m, H10, 2H), 5.31 (s, H7, 1H), 6.93-7.81 (m, H4, H2, H3, H5, H2', H5' , H3', $\left.\mathrm{H} 6^{\prime}, \mathrm{H}^{\prime}{ }^{\prime}, \mathrm{H} 6,10 \mathrm{H}\right), 8.49$ (d, J = 8.4 Hz, H1, 1H); ${ }^{13} \mathrm{C}-\mathrm{NMR}\left(\mathrm{CDCl}_{3}\right) 19.0\left(\mathrm{CH}_{2}, \mathrm{C} 11\right), 32.5\left(\mathrm{CH}_{2}, \mathrm{C} 12\right)$, 39.9 (CH, C7), $47.0\left(\mathrm{CH}_{2}, \mathrm{C} 10\right), 100.2(\mathrm{C}, \mathrm{C7a}), 118.6(\mathrm{CH}, \mathrm{C} 5), 121.6(\mathrm{CH}, \mathrm{C} 1), 123.8$ (C, C6a), 124.7 (CH, C3), $126.4(\mathrm{CH}, \mathrm{C} 6), 126.5(\mathrm{C}, \mathrm{C} 14 \mathrm{~b}), 126.8\left(\mathrm{CH}, \mathrm{C} 4^{\prime}\right), 127.5(\mathrm{CH}, \mathrm{C} 2), 128.4(\mathrm{CH}, \mathrm{C} 4), 128.5$ (2CH, C3' $\mathrm{C}^{\prime}$ ), 129.1 (2CH, C2' $\mathrm{C}^{\prime}$ ), 144.6 (C, C1'), 144.9 (C, C14a), 161.2 (C, C12a), 161.9 (C, C13a), 162.8 (C, C8). Anal. Calcd. for $\mathrm{C}_{24} \mathrm{H}_{18} \mathrm{~N}_{2} \mathrm{O}_{2}$ : C, 78.67; H, 4.95; N, 7.65. Found: C, 78.63; H, 4.97; N, 7.69.

7-Phenyl-10,11,12,13-tetrahydro-7H-benzo[7,8]chromeno[2,3-d]pyrido[1,2-a]pyrimidin-8-one (4Ab): Yield 90\%; mp $259{ }^{\circ} \mathrm{C}$; IR (KBr) $v_{\max } 1667,1572 \mathrm{~cm}^{-1}$; ${ }^{1} \mathrm{H}-\mathrm{NMR}\left(\mathrm{CDCl}_{3}\right)$ 1.92-1.94 (m, H10, 2H), 2.99-3.03 (m, H13, 2H), 3.88-3.91 (m, H11, H12, 4H), 5.33 (s, H7, 1H), 7.14-7.62 (m, H2, H3, H5, H2' , H5 ', $\mathrm{H}^{\prime}{ }^{\prime}, \mathrm{H}^{\prime}, \mathrm{H}^{\prime}$, $\mathrm{H6}, 9 \mathrm{H}), 7.79(\mathrm{~d}, J=8.1 \mathrm{~Hz}, \mathrm{H} 4,1 \mathrm{H}), 8.51(\mathrm{~d}, J=8.4 \mathrm{~Hz}, \mathrm{H1}, 1 \mathrm{H}) ;{ }^{13} \mathrm{C}-\mathrm{NMR}\left(\mathrm{CDCl}_{3}\right) 18.6\left(\mathrm{CH}_{2}, \mathrm{C} 12\right)$, $21.3\left(\mathrm{CH}_{2}, \mathrm{C} 11\right), 39.6(\mathrm{CH}, \mathrm{C} 7), 42.3\left(\mathrm{CH}_{2}, \mathrm{C} 10\right), 45.2\left(\mathrm{CH}_{2}, \mathrm{C} 13\right), 99.9(\mathrm{C}, \mathrm{C} 7 \mathrm{a}), 118.2(\mathrm{CH}, \mathrm{C} 5), 121.2$ $(\mathrm{CH}, \mathrm{C} 1), 123.4(\mathrm{C}, \mathrm{C} 6 \mathrm{a}), 124.0(\mathrm{CH}, \mathrm{C} 3), 125.8(\mathrm{CH}, \mathrm{C} 6), 126.0(\mathrm{C}, \mathrm{C} 15 \mathrm{~b}), 126.1\left(\mathrm{CH}, \mathrm{C4}{ }^{\prime}\right), 126.2(\mathrm{CH}$, C2), $127.0(\mathrm{CH}, \mathrm{C} 4), 127.9\left(2 \mathrm{CH}, \mathrm{C2}^{\prime}, \mathrm{C6}^{\prime}\right), 128.1\left(2 \mathrm{CH}, \mathrm{C}^{\prime}, \mathrm{C}^{\prime}\right), 132.7(\mathrm{C}, \mathrm{C} 4 \mathrm{a}), 144.1\left(\mathrm{C}, \mathrm{C1}^{\prime}\right), 144.5(\mathrm{C}$, C15a), 158.2 (C, C13a), 162.0 (C, C14a), 177.3 (C, C8). Anal. Calcd. for $\mathrm{C}_{25} \mathrm{H}_{20} \mathrm{~N}_{2} \mathrm{O}_{2}$ : C, 78.93; $\mathrm{H}, 5.30$; N, 7.36. Found: C, 78.97; H, 5.27; N, 7.32. 
7-Phenyl-11,12,13,14-tetrahydro-7H-benzo[7,8]chromeno $\left[2^{\prime}, 3^{\prime}, 4,5\right]$ pyrimido[1,2-a]azepin-8(10H)-one (4Ac): Yield 87\%; mp $228^{\circ} \mathrm{C}$; IR (KBr) $\gamma_{\max } 1659,1589 \mathrm{~cm}^{-1} ;{ }^{1} \mathrm{H}-\mathrm{NMR}\left(\mathrm{CDCl}_{3}\right) 1.76-1.87(\mathrm{~m}, \mathrm{H} 14, \mathrm{H} 13$, $\mathrm{H} 11, \mathrm{H} 12,8 \mathrm{H}), 3.02-3.04(\mathrm{~m}, \mathrm{H} 10,2 \mathrm{H}), 5.34(\mathrm{~s}, 1 \mathrm{H}, \mathrm{H} 7,1 \mathrm{H}), 7.14-7.62$ (m, H2, H3, H5, H2' $\mathrm{H}^{\prime}{ }^{\prime}, \mathrm{H}^{\prime}$, $\left.\mathrm{H6}^{\prime}, \mathrm{H} 4^{\prime}, \mathrm{H} 6,9 \mathrm{H}\right), 7.79$ (d, J = 8.1 Hz, H4, 1H), 8.51 (d, J = 8.4 Hz, H1, 1H); ${ }^{13} \mathrm{C}-\mathrm{NMR}\left(\mathrm{CDCl}_{3}\right) 27.3$ (CH, C13), $29.6\left(\mathrm{CH}_{2}, \mathrm{C} 12\right), 30.5\left(\mathrm{CH}_{2}, \mathrm{C} 11\right), 37.3\left(\mathrm{CH}_{2}, \mathrm{C} 14\right), 40.4(\mathrm{CH}, \mathrm{C} 7), 43.0\left(\mathrm{CH}_{2}, \mathrm{C} 10\right), 100.6(\mathrm{C}, \mathrm{C} 7 \mathrm{a})$, 118.7 (CH, C5), 121.7 (CH, C1), 123.8 (C, C6a), 124.5 (CH, C3), $126.3(\mathrm{CH}, \mathrm{C} 6), 126.5$ (C, C16b), 126.6 $\left(\mathrm{CH}, \mathrm{C}^{\prime}\right), 126.7(\mathrm{CH}, \mathrm{C} 2), 127.5(\mathrm{CH}, \mathrm{C} 4), 128.4\left(2 \mathrm{CH}, \mathrm{C}^{\prime}, \mathrm{C}^{\prime}\right), 128.5\left(2 \mathrm{CH}, \mathrm{C}^{\prime}, \mathrm{C}^{\prime}\right), 133.2$ (C, C4a), 144.5(C, C1'), 145.0 (C, C16a), 159.8 (C, C14a), 162.2 (C, C15a), 163.6 (C, C8). Anal. Calcd. for $\mathrm{C}_{26} \mathrm{H}_{22} \mathrm{~N}_{2} \mathrm{O}_{2}: \mathrm{C}, 79.17 ; \mathrm{H}, 5.62 ; \mathrm{N}, 7.10$. Found: $\mathrm{C}, 79.12 ; \mathrm{H}, 5.64 ; \mathrm{N}, 7.15$.

7-(3'-Methoxyphenyl)-11,12-dihydro-7H-benzo[7,8]chromeno[2,3-d]pyrrolo[1,2-a]pyrimidin-8(10H)-one (4Ba): Yield 81\%; mp $224{ }^{\circ} \mathrm{C}$; IR (KBr) $v_{\max } 1663,1577 \mathrm{~cm}^{-1}$; ${ }^{1} \mathrm{H}-\mathrm{NMR}\left(\mathrm{CDCl}_{3}\right) 2.22-2.27(\mathrm{~m}, \mathrm{H} 11,2 \mathrm{H})$, 3.18-3.20 (m, H12, 2H), $3.74\left(\mathrm{~s}, \mathrm{OCH}_{3}, 3 \mathrm{H}\right), 4.09-4.16(\mathrm{~m}, \mathrm{H} 10,2 \mathrm{H}), 5.36(\mathrm{~s}, \mathrm{H7}, 1 \mathrm{H}), 6.71(\mathrm{~d}, J=7.8 \mathrm{~Hz}$, $\mathrm{H} 6,1 \mathrm{H}), 6.91-7.60$ (m, H2, H3, H5, H2' $\left.{ }^{\prime} \mathrm{H}^{\prime}, \mathrm{H}^{\prime}, \mathrm{H} 4^{\prime}, 7 \mathrm{H}\right), 7.81(\mathrm{~d}, J=7.8 \mathrm{~Hz}, \mathrm{H} 4,1 \mathrm{H}), 8.49$ (d, $J=8.4 \mathrm{~Hz}, \mathrm{H1}, 1 \mathrm{H}) ;{ }^{13} \mathrm{C}-\mathrm{NMR}\left(\mathrm{CDCl}_{3}\right) 19.1(\mathrm{CH}, \mathrm{C} 11), 32.5(\mathrm{CH}, \mathrm{C} 12), 39.9(\mathrm{CH}, \mathrm{C} 7), 47.0(\mathrm{CH}, \mathrm{C} 10)$, $55.1\left(\mathrm{OCH}_{3}\right), 100.7(\mathrm{C}, \mathrm{C} 7 \mathrm{a}), 111.9\left(\mathrm{CH}, \mathrm{C}^{\prime}\right), 114.1\left(\mathrm{CH}, \mathrm{C}^{\prime}\right), 118.4(\mathrm{CH}, \mathrm{C} 5), 120.9\left(\mathrm{CH}, \mathrm{C6}^{\prime}\right), 121.6$ (C, C6a), $123.8(\mathrm{CH}, \mathrm{C} 1), 124.7$ (C, C14b), $126.4(\mathrm{CH}, \mathrm{C} 3), 126.6$ (2CH, C2, C6), $127.5(\mathrm{CH}, \mathrm{C} 4), 129.3$ (CH, C5'), 133.3 (C, C4a), 144.5 (C, C1'), 146.5 (C, C14a), 159.6 (C, C12a), 161.1 (C, C13a), 161.8 (C, C8), $162.8\left(\mathrm{C}, \mathrm{C}^{\prime}\right.$ ). Anal. Calcd. for $\mathrm{C}_{25} \mathrm{H}_{20} \mathrm{~N}_{2} \mathrm{O}_{3}$ : C, 75.74; H, 5.09; N, 7.07. Found: C, 75.72; H, 5.11; N, 7.12.

7-(3'-Methoxyphenyl)-10,11,12,13-tetrahydro-7H-benzo[7,8]chromeno[2,3-d]pyrido[1,2-a]pyrimidin-8-one (4Bb): Yield 90\%; mp $238^{\circ} \mathrm{C}$; IR (KBr) $v_{\max } 1661,1572 \mathrm{~cm}^{-1} ;{ }^{1} \mathrm{H}-\mathrm{NMR}\left(\mathrm{CDCl}_{3}\right) 1.89-1.94$ (m, 4H, H11, $\mathrm{H} 12,4 \mathrm{H}), 2.88-2.95(\mathrm{~m}, \mathrm{H} 13,2 \mathrm{H}), 3.71\left(\mathrm{~s}, \mathrm{OCH}_{3}, 3 \mathrm{H}\right), 3.87-3.89(\mathrm{~m}, \mathrm{H} 10,2 \mathrm{H}), 5.31(\mathrm{~s}, \mathrm{H} 7,1 \mathrm{H}), 6.69(\mathrm{~d}$, $J=8.1 \mathrm{~Hz}, \mathrm{H} 6,1 \mathrm{H}), 6.89-7.59\left(\mathrm{~m}, \mathrm{H} 2, \mathrm{H} 3, \mathrm{H} 5, \mathrm{H} 2^{\prime}, \mathrm{H}^{\prime}, \mathrm{H}^{\prime}, \mathrm{H}^{\prime}, 7 \mathrm{H}\right), 7.76(\mathrm{~d}, J=7.8 \mathrm{~Hz}, \mathrm{H} 4,1 \mathrm{H})$, $8.48(\mathrm{~d}, J=8.4 \mathrm{~Hz}, \mathrm{H1}, 1 \mathrm{H}) ;{ }^{13} \mathrm{C}-\mathrm{NMR}\left(\mathrm{CDCl}_{3}\right) 18.6(\mathrm{CH}, \mathrm{C} 12), 21.3(\mathrm{CH}, \mathrm{C} 11), 31.1(\mathrm{CH}, \mathrm{C} 13), 39.6$ $(\mathrm{CH}, \mathrm{C} 7), 42.4(\mathrm{CH}, \mathrm{C} 10), 54.6\left(\mathrm{OCH}_{3}\right), 99.7(\mathrm{C}, \mathrm{C} 7 \mathrm{a}), 111.3\left(\mathrm{CH}, \mathrm{C4}^{\prime}\right), 114.1\left(\mathrm{CH}, \mathrm{C}^{\prime}\right), 118.1(\mathrm{CH}, \mathrm{C} 5)$, 120.5 (CH, C6'), 121.2 (C, C6a), $123.4(\mathrm{CH}, \mathrm{C} 1), 124.0$ (C, C15b), $125.8(\mathrm{CH}, \mathrm{C} 3), 126.0$ (2CH, C2, C6), 127.0 (CH, C4), $128.8\left(\mathrm{CH}, \mathrm{C}^{\prime}\right), 132.7$ (C, C4a), 143.9 (C, C1'), 146.2 (C, C15a), 158.2 (C, C13a), 159.1 (C, C14a), $159.4(\mathrm{C}, \mathrm{C} 8), 162.0\left(\mathrm{C}, \mathrm{C}^{\prime}\right)$. Anal. Calcd. for $\mathrm{C}_{26} \mathrm{H}_{22} \mathrm{~N}_{2} \mathrm{O}_{3}$ : $\mathrm{C}, 76.08 ; \mathrm{H}, 5.40 ; \mathrm{N}, 6.82$. Found: C, $76.12 ; \mathrm{H}, 5.37 ; \mathrm{N}, 6.79$.

7-(3'-Methoxyphenyl)-11,12,13,14-tetrahydro-7H-benzo[7,8]chromeno[2',3', 4,5]pyrimido[1,2-a]azepin-8(10H)-one (4Bc): Yield 79\%; mp $215^{\circ} \mathrm{C}$; IR (KBr) $v_{\max } 1662,1577 \mathrm{~cm}^{-1} ;{ }^{1} \mathrm{H}-\mathrm{NMR}\left(\mathrm{CDCl}_{3}\right) 1.80-2.11(\mathrm{~m}, \mathrm{H} 14, \mathrm{H} 11$, $\mathrm{H} 13, \mathrm{H} 12,8 \mathrm{H}), 3.10-3.17(\mathrm{~m}, \mathrm{H} 10,2 \mathrm{H}), 4.10\left(\mathrm{~s}, \mathrm{OCH}_{3}, 3 \mathrm{H}\right), 5.29(\mathrm{~s}, \mathrm{H} 7,1 \mathrm{H}), 6.70(\mathrm{~d}, J=7.8 \mathrm{~Hz}, \mathrm{H} 6,1 \mathrm{H})$, 6.89-7.62 (m, H2, H3, H5, H2' $\left.{ }^{\prime} \mathrm{H}^{\prime}, \mathrm{H}^{\prime}, \mathrm{H}^{\prime}, 7 \mathrm{H}\right), 7.79(\mathrm{~d}, J=7.8 \mathrm{~Hz}, \mathrm{H} 4,1 \mathrm{H}), 8.51(\mathrm{~d}, J=8.1 \mathrm{~Hz}, \mathrm{H} 1$, $1 \mathrm{H}) ;{ }^{13} \mathrm{C}-\mathrm{NMR}\left(\mathrm{CDCl}_{3}\right) 24.0(\mathrm{CH}, \mathrm{C} 12), 26.7(\mathrm{CH}, \mathrm{C} 13), 29.1(\mathrm{CH}, \mathrm{C} 11), 36.4(\mathrm{CH}, \mathrm{C} 14), 39.8(\mathrm{CH}, \mathrm{C} 7)$, $42.6(\mathrm{CH}, \mathrm{C} 10), 54.6\left(\mathrm{OCH}_{3}\right), 100.0(\mathrm{C}, \mathrm{C} 7 \mathrm{a}), 111.4\left(\mathrm{CH}, \mathrm{C}^{\prime}\right), 114.1\left(\mathrm{CH}, \mathrm{C}^{\prime}\right), 118.0(\mathrm{CH}, \mathrm{C} 5), 120.5(\mathrm{CH}$, $\left.\mathrm{C}^{\prime}\right), 121.2$ (C, C6a), $123.3(\mathrm{CH}, \mathrm{C} 1), 124.1$ (C, C16b), $125.2(\mathrm{CH}, \mathrm{C} 3), 125.9$ (2CH, C2,C6), 126.1 (CH, C4), 126.9 (CH, C5'), 128.8 (C, C4a), 132.7 (C, C1'), 143.8 (C, C16a), 146.0 (C, C14a), 159.1 (C, C15a), 161.4 (C, C8), $163.3\left(\mathrm{C}, \mathrm{C}^{\prime}\right)$. Anal. Calcd. for $\mathrm{C}_{27} \mathrm{H}_{24} \mathrm{~N}_{2} \mathrm{O}_{3}$ : C, 76.40; $\mathrm{H}, 5.70 ; \mathrm{N}, 6.60$. Found: C, 76.37; $\mathrm{H}, 5.72 ; \mathrm{N}, 6.63$.

7-(4'-Methylphenyl)-11,12-dihydro-7H-benzo[7,8]chromeno[2,3-d]pyrrolo[1,2-a]pyrimidin-8(10H)-one (4Ca): Yield 78\%; mp > $260{ }^{\circ} \mathrm{C}$; IR (KBr) $v_{\max } 1661,1589 \mathrm{~cm}^{-1} ;{ }^{1} \mathrm{H}-\mathrm{NMR}\left(\mathrm{CDCl}_{3}\right) 2.14-2.21(\mathrm{~m}, \mathrm{H} 11,2 \mathrm{H}), 2.27$ (s, $\left.\mathrm{CH}_{3}, 3 \mathrm{H}\right), 3.11-3.22(\mathrm{~m}, \mathrm{H} 12,2 \mathrm{H}), 4.05-4.12(\mathrm{~m}, \mathrm{H} 10,2 \mathrm{H}), 5.35(\mathrm{~s}, \mathrm{H} 7,1 \mathrm{H}), 7.06\left(\mathrm{~d}, J=7.8 \mathrm{~Hz}, \mathrm{H} 3^{\prime}\right.$, $\left.\mathrm{H} 5^{\prime}, 2 \mathrm{H}\right), 7.17(\mathrm{~d}, J=8.7 \mathrm{~Hz}, \mathrm{H6}, 1 \mathrm{H}), 7.25\left(\mathrm{~d}, J=7.8 \mathrm{~Hz}, \mathrm{H}^{\prime}, \mathrm{H}^{\prime}, 2 \mathrm{H}\right), 7.51-7.62(\mathrm{~m}, \mathrm{H} 2, \mathrm{H} 3, \mathrm{H} 5,3 \mathrm{H})$, $7.72(\mathrm{~d}, J=8.4 \mathrm{~Hz}, \mathrm{H} 4,1 \mathrm{H}) 8.49(\mathrm{~d}, J=8.4 \mathrm{~Hz}, \mathrm{H1}, 1 \mathrm{H}) ;{ }^{13} \mathrm{C}-\mathrm{NMR}\left(\mathrm{CDCl}_{3}\right) 19.11\left(\mathrm{CH}_{2}, \mathrm{C} 11\right), 21.0\left(\mathrm{CH}_{3}\right)$, $32.5\left(\mathrm{CH}_{2}, \mathrm{C} 12\right), 39.5(\mathrm{CH}, \mathrm{C} 7), 46.9\left(\mathrm{CH}_{2}, \mathrm{C} 10\right), 101.0(\mathrm{C}, \mathrm{C} 7 \mathrm{a}), 118.7(\mathrm{CH}, \mathrm{C} 5), 121.5(\mathrm{CH}, \mathrm{C} 1), 124.6$ (C, C6a), $126.5(\mathrm{CH}, \mathrm{C} 3), 126.6(\mathrm{CH}, \mathrm{C} 6), 127.1(\mathrm{CH}, \mathrm{C} 2), 127.5(\mathrm{C}, \mathrm{C} 14 \mathrm{~b}), 128.4(\mathrm{CH}, \mathrm{C} 4), 129.1$ $\left(2 \mathrm{CH}, \mathrm{C}^{\prime}, \mathrm{C}^{\prime}\right), 129.8\left(2 \mathrm{CH}, \mathrm{C}^{\prime}, \mathrm{C}^{\prime}\right), 133.2(\mathrm{C}, \mathrm{C} 4 \mathrm{a}), 136.4\left(\mathrm{C}, \mathrm{C} 4^{\prime}\right), 142.1\left(\mathrm{C}, \mathrm{C} 1^{\prime}\right), 144.5(\mathrm{C}, \mathrm{C} 14 \mathrm{a})$, 161.2 (C, C12a), 161.8 (C, C13a), 162.7 (C, C8). Anal. Calcd. for $\mathrm{C}_{25} \mathrm{H}_{20} \mathrm{~N}_{2} \mathrm{O}_{2}: \mathrm{C}, 78.93 ; \mathrm{H}, 5.30 ; \mathrm{N}, 7.36$. Found: C, 78.97; H, 5.27; N, 7.38. 
7-(4'-Methylphenyl)-10,11,12,13-tetrahydro-7H-benzo[7,8]chromeno[2,3-d]pyrido[1,2-a]pyrimidin-8-one (4Cb): Yield 86\%; mp $224^{\circ} \mathrm{C}$; IR (KBr) $v_{\max } 1667,1571 \mathrm{~cm}^{-1},{ }^{1} \mathrm{H}-\mathrm{NMR}\left(\mathrm{CDCl}_{3}\right)$ 1.92-1.99 (m, H11,H12, 4H), $2.27\left(\mathrm{~s}, \mathrm{CH}_{3}, 3 \mathrm{H}\right), 3.02-3.10(\mathrm{~m}, \mathrm{H13}, 2 \mathrm{H}), 3.90-3.96(\mathrm{~m}, \mathrm{H10}, 2 \mathrm{H}), 5.29(\mathrm{~s}, \mathrm{H} 7,1 \mathrm{H}), 7.06(\mathrm{~d}, J=7.8 \mathrm{~Hz}$, $\left.\mathrm{H3}^{\prime}, \mathrm{H}^{\prime}, 2 \mathrm{H}\right), 7.14(\mathrm{~d}, J=8.1 \mathrm{~Hz}, \mathrm{H6}, 1 \mathrm{H}), 7.23\left(\mathrm{~d}, \mathrm{~J}=7.8 \mathrm{~Hz}, \mathrm{H} 2^{\prime}, \mathrm{H6}^{\prime}, 2 \mathrm{H}\right), 7.52-7.63$ (m, H2, H3, H5, 3H), $7.79(\mathrm{~d}, J=7.8 \mathrm{~Hz}, \mathrm{H} 4,1 \mathrm{H}), 8.52(\mathrm{~d}, J=8.4 \mathrm{~Hz}, \mathrm{H} 1,1 \mathrm{H}) ;{ }^{13} \mathrm{C}-\mathrm{NMR}\left(\mathrm{CDCl}_{3}\right) 18.9\left(\mathrm{CH}_{2}, \mathrm{C} 12\right), 21.0$ $\left(\mathrm{CH}_{3}\right), 21.7\left(\mathrm{CH}_{2}, \mathrm{C} 11\right), 31.2\left(\mathrm{CH}_{2}, \mathrm{C} 13\right), 39.6(\mathrm{CH}, \mathrm{C} 7), 42.9\left(\mathrm{CH}_{2}, \mathrm{C} 10\right), 100.6(\mathrm{C}, \mathrm{C} 7 \mathrm{a}), 118.7(\mathrm{CH}, \mathrm{C} 5)$, 123 (CH, C1), 124.7 (C, C6a), 126.5 (2CH, C3, C6), 127.0 (CH, C2), 127.5 (C, C15b), 127.8 (CH, C4), 128.4

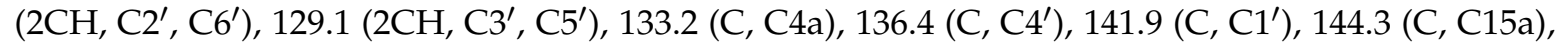
158.9 (C, C13a), 159.1 (C, C14a), 162.1 (C, C8). Anal. Calcd. for $\mathrm{C}_{26} \mathrm{H}_{22} \mathrm{~N}_{2} \mathrm{O}_{2}$ : C, 79.17; H, 5.62; N, 7.10. Found: C, 79.21; H, 5.59; N, 7.14 .

17-(4'-Methylphenyl)-11,12,13,14-tetrahydro-7H-benzo[7,8]chromeno[2',3',4,5]pyrimido[1,2-a]azepin-8(10H)-one (4Cc): Yield 70\%; $\mathrm{mp}>260{ }^{\circ} \mathrm{C}$; IR (KBr) $v_{\max } 1664,1593 \mathrm{~cm}^{-1} ;{ }^{1} \mathrm{H}-\mathrm{NMR}\left(\mathrm{CDCl}_{3}\right) 1.74-1.81$ (m, H12, 2H), 1.85-1.96 (m, H11, H13, H14, 6H), 2.27 (s, $\left.\mathrm{CH}_{3}, 3 \mathrm{H}\right), 3.02-3.11$ (m, H10, 2H), 5.30 (s, H7, 1H), 7.06 $\left(\mathrm{d}, J=7.8 \mathrm{~Hz}, \mathrm{H3}^{\prime}, \mathrm{H} 5,2 \mathrm{H}^{\prime}\right), 7.14(\mathrm{~d}, J=8.1 \mathrm{~Hz}, \mathrm{H6}, 1 \mathrm{H}), 7.24\left(\mathrm{~d}, J=7.8 \mathrm{~Hz}, \mathrm{H2}{ }^{\prime}, \mathrm{H6}{ }^{\prime}, 2 \mathrm{H}\right), 7.50-7.62(\mathrm{~m}$, $\mathrm{H} 2, \mathrm{H} 3, \mathrm{H} 5,3 \mathrm{H}), 7.70(\mathrm{~d}, J=7.8 \mathrm{~Hz}, \mathrm{H} 4,1 \mathrm{H}), 7.79(\mathrm{~d}, \mathrm{~J}=8 \mathrm{~Hz}, \mathrm{H} 1,1 \mathrm{H}) ;{ }^{13} \mathrm{C}-\mathrm{NMR}\left(\mathrm{CDCl}_{3}\right) 21.0\left(\mathrm{CH}_{3}\right)$, $24.6\left(\mathrm{CH}_{2}, \mathrm{C} 12\right), 27.3\left(\mathrm{CH}_{2}, \mathrm{C} 13\right), 29.6\left(\mathrm{CH}_{2}, \mathrm{C} 11\right), 37.3\left(\mathrm{CH}_{2}, \mathrm{C} 14\right), 40.0(\mathrm{CH}, \mathrm{C} 7), 43.0\left(\mathrm{CH}_{2}, \mathrm{C} 10\right), 100.7$ (C, C7a), 118.9 (CH, C5), 121.7 (CH, C1), 123.9 (C, C6a), 124.5 (CH, C3), 126.6 (CH, C6), 127.2 (C, C16b), $127.8(\mathrm{CH}, \mathrm{C} 4), 128.4\left(2 \mathrm{CH}, \mathrm{C}^{\prime}, \mathrm{C}^{\prime}\right), 129.1\left(2 \mathrm{CH}, \mathrm{C}^{\prime}, \mathrm{C}^{\prime}\right), 133.2(\mathrm{C}, \mathrm{C} 4 \mathrm{a}), 136.3\left(\mathrm{C}, \mathrm{C}^{\prime}\right), 142.2\left(\mathrm{C}, \mathrm{C}^{\prime}\right)$, 144.4 (C, C16a), 159.7 (C, C14a), 162.1 (C, C15a), 163.5 (C, C8). Anal. Calcd. For $\mathrm{C}_{27} \mathrm{H}_{24} \mathrm{~N}_{2} \mathrm{O}_{2}$ : C, 79.39 ; H, 5.92; N, 6.86. Found: C, 79.35; H, 5.94; N, 6.89.

\subsection{Oxygen Radical Absorbance Capacity Assay}

The antioxidant power of BCPOs was determined following the ORAC-FL method using fluorescein as the fluorescent probe [20,21]. ( \pm )-6-Hydroxy-2,5,7,8-tetramethylchromane-2-carboxylic acid (Trolox), fluorescein (FL) and AAPH were bought from Sigma-Aldrich (Saint Louis, MO, USA). A Varioskan Flash plate reader with built-in injectors (Thermo Scientific, Waltham, MA, USA) was used. The final volume reaction mixture was $200 \mu \mathrm{L}$ and the reaction was carried out at $37^{\circ} \mathrm{C}$ in $75 \mathrm{mM}$ phosphate buffer ( $\mathrm{pH}$ 7.4). The tested compounds and Trolox standard were dissolved in DMSO to $10 \mathrm{mM}$ and further diluted in phosphate buffer. The final concentrations were $0.1-1 \mu \mathrm{M}$ for the tested compounds and 1-8 $\mu \mathrm{M}$ for Trolox standard. The blank was composed of $120 \mu \mathrm{L}$ of FL, $60 \mu \mathrm{L}$ of AAPH and $20 \mu \mathrm{L}$ of phosphate buffer $(\mathrm{pH}=7.4)$ and was added in each assay. The antioxidant $(20 \mu \mathrm{L})$ and fluorescein (FL, $120 \mu \mathrm{L}$, final concentration of $70 \mathrm{nM}$ ) were incubated in a black 96-well microplate Nunc, purchazed from Thermo Fisher Scientific, Ecublens, Switzerland) for $15 \mathrm{~min}$ at $37^{\circ} \mathrm{C}$. Then, AAPH, $60 \mu \mathrm{L}$, final concentration of $12 \mathrm{mM}$ ) solution was added quickly using the built-in injector. The fluorescence decay was measured every minute for $60 \mathrm{~min}$ at $\lambda_{\mathrm{ex}}=485 \mathrm{~nm}$ and $\lambda_{\mathrm{em}}=535 \mathrm{~nm}$. The microplate was automatically shaken prior to each reading. All the experiments were made in triplicate and at least three different assays were performed for each sample. Antioxidant curves (fluorescence versus time) were first normalized to the curve of the blank (without antioxidant) and then, the area under the fluorescence decay curve (AUC) was calculated as:

$$
\mathrm{AUC}=1+\operatorname{sum}\left(f_{\mathrm{i}} / f_{0}\right)
$$

where $f_{0}$ is the initial fluorescence reading at 0 min and $f_{i}$ is the fluorescence value at time $i$. The net AUC corresponding to the sample was calculated as follows:

$$
\text { Net } \mathrm{AUC}=\mathrm{AUC}_{\text {antioxidant }}-\mathrm{AUC}_{\mathrm{blank}}
$$

Using MS Excel software, regression equations were extrapolated by plotting the net AUC against the antioxidant concentration. The ORAC values were then obtained by dividing the slope of the latter 
curve between the slope of the Trolox curve obtained in the same assay. Final ORAC values were expressed as Trolox equivalents. Data are expressed as mean \pm SD.

\subsection{Inhibition of EeAChE and EqBuChE}

Assessment of the inhibitory power of BCPOs was performed following the spectrophotometric method of Ellman [23] using purified AChE from Electrophorus electricus (Type V-S, Sigma-Aldrich) or BuChE from horse serum (lyophilized powder, Sigma-Aldrich). Enzymes were first dissolved in $0.1 \mathrm{M}$ phosphate buffer ( $\mathrm{pH}$ 8.0) and then aliquoted in small vials for easy handling. Compounds stock solutions in DMSO $(10 \mathrm{mM})$ were diluted when necessary with DMSO to prepare appropriate dilutions of each compound. The assay was performed in a final volume of $3 \mathrm{~mL}$ of a $0.1 \mathrm{M}$ phosphate-buffered solution at $\mathrm{pH} 8.0$, containing 5,5'-dithiobis-2-nitrobenzoic acid (DTNB, $2625 \mu \mathrm{L}, 0.35 \mathrm{mM}$, final concentration), EeAChE $(29 \mu \mathrm{L}, 0.035 \mathrm{U} / \mathrm{mL}$ final concentration) or $e q \mathrm{BuChE}(60 \mu \mathrm{L}, 0.05 \mathrm{U} / \mathrm{mL}$ final concentration) tested compound ( $3 \mu \mathrm{L}$, different concentrations) and 1\% $(w / v)$ Bovine Albumin Serum phosphate-buffered ( $\mathrm{pH}$ 8.0) solution (BSA, $40 \mu \mathrm{L}$ ). The inhibition in comparison to control without compound was determined by pre-incubating this blend at room temperature with each compound at nine different concentrations for $10 \mathrm{~min}$. Then, acetylthiocholine iodide $(105 \mu \mathrm{L}, 0.35 \mathrm{mM}$, final concentration) or butyrylthiocholine iodide $(150 \mu \mathrm{L}, 0.5 \mathrm{mM}$ final concentration) was added and incubated for another $15 \mathrm{~min}$ at $\mathrm{rt}$. The absorbances were measured at $412 \mathrm{~nm}$ in a plate reader (iEMS Reader MF, Labsystems, Thermo fisher scientific Ecublens, Switzerland). The percentage of inhibition of the enzyme was calculated in comparison with the blank sample (100\% enzyme activity). Calculation of $\mathrm{IC}_{50}$ values was performed with GraphPad Prism 5. Each concentration was measured in triplicate. Data are expressed as mean \pm SEM.

\subsection{Inhibition of $h A C h E$}

Ellman's assay was followed to evaluate the anticholinesterasic potency of BCPOs [23] using human recombinant AChE (Sigma-Aldrich). $500 \mathrm{U}$ of $h \mathrm{AChE}$ were dissolved in $1 \mathrm{~mL}$ of a gelatine solution (1\% in water) and diluted with demineralized water to give a stock solution of $5 \mathrm{U} / \mathrm{mL}$. The $12.5 \mathrm{mM}$ 5,5'-dithiobis-(2-nitrobenzoic acid) (DTNB, Ellman's reagent) solution containing $0.15 \%$ $(w / v)$ sodium carbonate and $18.75 \mathrm{mM}$ acetylthiocholine (ATC) iodide solution were prepared in demineralized water. All assays were performed in $0.1 \mathrm{M}$ phosphate buffer $\mathrm{pH}$ 8.0. The assayed compounds or blank (water) $(25 \mu \mathrm{L})$ were incubated with the enzyme $(20 \mu \mathrm{L})$ for 5 min at $37^{\circ} \mathrm{C}$ in $765 \mu \mathrm{L}$ of phosphate buffer prior to start the reaction. Then, $20 \mu \mathrm{L}$ of DTNB and $20 \mu \mathrm{L}$ of ATC were added. After $5 \mathrm{~min}$, absorbances were measured at $412 \mathrm{~nm}$ with an EnSpire Multimode microplate reader (Perkin-Elmer, Waltham, MA, USA). The percentage of inhibition of the enzyme was calculated by comparison with a blank sample (100\% enzyme activity). IC I $_{50}$ values were determined with GraphPad Prism 5. Each concentration was measured in triplicate. Data are expressed as mean \pm SEM.

\subsection{Kinetic Characterization of hAChE Inhibition}

To estimate the type of inhibition of $h \mathrm{AChE}$, we performed the same experimental protocol as reported for $h \mathrm{AChE}$ inhibition. Different concentrations of the substrate ATC (0.067-0.5 mM) were used to create Lineweaver-Burk plots by plotting the inverse initial velocity $(1 / V)$ as a function of the inverse of the substrate concentration (1/[S]). The stock solution of ATC $(0.5 \mathrm{mM}$ in a well) was prepared in demineralized water and diluted before use to obtain $0.4,0.3,0.2,0.1$ and $0.067 \mathrm{mM}$ substrate solutions. The double reciprocal plots were analysed by a weighted least square procedure that assumed the variance of $V$ to be constant. Each experiment was performed in triplicate. To confirm the mode of inhibition, Cornish-Bowden plots were obtained by plotting $S / V$ (substrate/velocity ratio) versus the inhibitor concentration [23,28]. Data analysis was performed with GraphPad Prism 5. Inhibition constant $\left(\mathrm{K}_{\mathrm{i}}\right)$ values were determined by re-plotting slopes from the Lineweaver-Burk plot versus the inhibitor concentration where $\mathrm{K}_{\mathrm{i}}$ was determined as the intersect of the line with the $\mathrm{x}$-axis [29]. 


\subsection{In vitro Toxicity of Compounds $\mathbf{3} \mathbf{A b}, 3 \mathbf{B b}, \mathbf{3 C b}$ and $\mathbf{3 B a}$ in HepG2 Cells}

HepG2 cells were purchased from American Type Culture Collection. The cells were cultured in Eagle's Minimum Essential Medium (Ozyme, France) supplemented with 10\% fetal bovine serum, 1X non-essential amino acids, 100 units $/ \mathrm{mL}$ penicillin and $10 \mathrm{mg} / \mathrm{mL}$ streptomycin (Dutscher, Brumath, France). Cultures were kept under a $\mathrm{CO}_{2} /$ air $(5 \% / 95 \%)$ humidified atmosphere at $37^{\circ} \mathrm{C}$. Prior to the experiment, cells were seeded in 96-well culture plates at a density of $0.1 \times 10^{6}$ cells per well. After $24 \mathrm{~h}$ of incubation, the culture medium was refreshed and $100 \mu \mathrm{L}$ of the test compounds or DMSO $(0.1 \%)$ were added. Compounds were tested at 4 concentrations $(1-30 \mu \mathrm{M})$ in triplicate. For the MTT assay [25], after $24 \mathrm{~h}$ of treatment, cells were incubated with $50 \mu \mathrm{L}$ MTT $(0.5 \mathrm{mg} / \mathrm{mL}$, Sigma Aldrich, city, France) at $37^{\circ} \mathrm{C}$ for $2 \mathrm{~h}$. Plates were centrifuged, MTT was removed and $100 \mu \mathrm{L}$ DMSO was distributed per well. The absorbance at $570 \mathrm{~nm}$ was measured using microplate reader (brand). Cell viability was expressed as percentage of cell viability compared to controls (DMSO, $0.1 \%$ ).

\subsection{PAMPA Assay}

Penetration across the BBB is an essential property for compounds targeting the CNS. In order to predict passive blood-brain penetration of novel compounds modification of the PAMPA has been used based on reported protocol [26,27]. The filter membrane of the donor plate was coated with PBL (Polar Brain Lipid, Avanti, AL, USA) in dodecane $(4 \mu \mathrm{L}$ of $20 \mathrm{mg} / \mathrm{mL}$ PBL in dodecane) and the acceptor well was filled with $300 \mu \mathrm{L}$ of PBS pH 7.4 buffer $\left(\mathrm{V}_{\mathrm{D}}\right)$. Tested compounds were dissolved first in DMSO and that diluted with PBS pH 7.4 to reach the final concentration $100 \mu \mathrm{M}$ in the donor well. Concentration of DMSO did not exceed $0.5 \%(v / v)$ in the donor solution. $300 \mu \mathrm{L}$ of the donor solution was added to the donor wells $\left(\mathrm{V}_{\mathrm{A}}\right)$ and the donor filter plate was carefully put on the acceptor plate so that coated membrane was "in touch" with both donor solution and acceptor buffer. Test compound diffused from the donor well through the lipid membrane (Area $=0.28 \mathrm{~cm}^{2}$ ) to the acceptor well. The concentration of the drug in both donor and the acceptor wells was assessed after 3, 4, 5 and $6 \mathrm{~h}$ of incubation in quadruplicate using the UV plate reader Synergy HT (Biotek, Winooski, VT, USA) at the maximum absorption wavelength of each compound. Concentration of the compounds was calculated from the standard curve and expressed as the permeability (Pe) according the Equation (1) [30,31]:

$$
\log P_{e}=\log \left\{C \times-\ln \left(1-\frac{[\text { drug }]_{\text {acceptor }}}{[d r u g]_{\text {equilibrium }}}\right)\right\} \text { where } C=\left(\frac{V_{D} \times V_{A}}{\left(V_{D}+V_{A}\right) \times \text { Area } \times \text { time }}\right)
$$

\section{Conclusions}

We have synthesized and evaluated eighteen new benzochromenopyrimidinones as promising multitarget-directed ligands with marked selectivity for AChE and good antioxidant activity. Particularly, compounds $\mathbf{3 A b}, \mathbf{3 B b}, \mathbf{3 C b}$ and $\mathbf{3 B a}$ were found to be non-hepatotoxic and moderate $h$ AChEIs. Among them, although compound $\mathbf{3 B b}$ showed a Pe value in an uncertain interval and consequently, a compromised permeability, this benzochromenopyrimidinone is a micromolar mixed-type $h \mathrm{AChE}$ inhibitor $\left(\mathrm{IC}_{50}=1.28 \mu \mathrm{M}\right)$ and a potent antioxidant $(4.7 \mathrm{TE})$. To sum up, this small library of benzochromenopyrimidinones constitutes an additional step in our laboratory towards the search for lead compounds with polypharmacological properties as potential new anti-AD agents.

Supplementary Materials: Supplementary materials can be accessed at: http://www.mdpi.com/1420-3049/ 21/5/634/s1.

Acknowledgments: JMC thanks Government of Spain for support (SAF2016-65586-R), JJ and OS thank MH CZ- DRO (UHHK 00179906).

Author Contributions: Y.D. did the synthesis; O.M.B.-A. evaluated the inhibition potency on the cholinesterases; M.B. carried out the antioxidant power analysis of the hybrids and corrected the manuscript. D.K. performed the $\mathrm{A} \beta$ test and corrected the manuscript. A.B. did the hepatotoxicity study, H.M. designed the HepG2 test and analyzed the results. J.G. performed the $h \mathrm{AChE}$ and the kinetic study. B.M. supervised the $h \mathrm{AChE}$ assay, kinetic study and corrected the manuscript. S.G. supervised the A $\beta$ test and corrected the manuscript. F.C. conceived the 
project and supervised the synthesis. M.C. and J.M.-C. corrected the manuscript. J.J. and O.S. did the PAMPA assay. L.I. supervised and coordinated the pharmacological studies in Besançon (France), wrote and corrected the manuscript.

Conflicts of Interest: The authors declare no conflict of interest.

\section{References}

1. World Alzheimer Report 2015. Available online: http://www.worldalzreport2015.org/ (accessed on 3 February 2016).

2. Liu, L.; Luo, S.; Zeng, L.; Wang, W.; Yuan, L.; Jian, X. Degenerative alterations in noradrenergic neurons of the locus coeruleus in Alzheimer's disease. Neural Regen. Res. 2013, 8, 2249-2255. [PubMed]

3. Mesulam, M.-M. Cholinergic circuitry of the human nucleus basalis and its fate in Alzheimer's disease. J. Comp. Neurol. 2013, 521, 4124-4144. [CrossRef] [PubMed]

4. Zarow, C.; Lyness, S.A.; Mortimer, J.A.; Chui, H.C. Neuronal loss is greater in the locus coeruleus than nucleus basalis and substantia nigra in alzheimer and parkinson diseases. Arch. Neurol. 2003, 60, 337-341.

5. Praticò, D.; Sung, S. Lipid peroxidation and oxidative imbalance: Early functional events in Alzheimer's disease. J. Alzheimers Dis. JAD 2004, 6, 171-175. [PubMed]

6. Yan, M.H.; Wang, X.; Zhu, X. Mitochondrial defects and oxidative stress in Alzheimer disease and Parkinson disease. Free Radic. Biol. Med. 2013, 62, 90-101. [CrossRef] [PubMed]

7. Greenough, M.A.; Camakaris, J.; Bush, A.I. Metal dyshomeostasis and oxidative stress in Alzheimer's disease. Neurochem. Int. 2013, 62, 540-555. [CrossRef] [PubMed]

8. Candore, G.; Bulati, M.; Caruso, C.; Castiglia, L.; Colonna-Romano, G.; di Bona, D.; Duro, G.; Lio, D.; Matranga, D.; Pellicanò, M.; et al. Inflammation, cytokines, immune response, apolipoprotein E, cholesterol, and oxidative stress in Alzheimer disease: Therapeutic implications. Rejuvenation Res. 2010, 13, 301-313. [CrossRef] [PubMed]

9. Bond, M.; Rogers, G.; Peters, J.; Anderson, R.; Hoyle, M.; Miners, A.; Moxham, T.; Davis, S.; Thokala, P.; Wailoo, A.; et al. The effectiveness and cost-effectiveness of donepezil, galantamine, rivastigmine and memantine for the treatment of Alzheimer's disease (review of Technology Appraisal No. 111): A systematic review and economic model. Health Technol. Assess. 2012, 16. [CrossRef] [PubMed]

10. Wilkinson, D.; Wirth, Y.; Goebel, C. Memantine in Patients with Moderate to Severe Alzheimer's Disease: Meta-Analyses Using Realistic Definitions of Response. Dement. Geriatr. Cogn. Disord. 2014, 37, 71-85. [CrossRef] [PubMed]

11. Watkins, P.B.; Zimmerman, H.J.; Knapp, M.J.; Gracon, S.I.; Lewis, K.W. Hepatotoxic effects of tacrine administration in patients with Alzheimer's disease. JAMA 1994, 271, 992-998. [CrossRef] [PubMed]

12. Bolea, I.; Juárez-Jiménez, J.; de los Ríos, C.; Chioua, M.; Pouplana, R.; Luque, F.J.; Unzeta, M.; Marco-Contelles, J.; Samadi, A. Synthesis, Biological Evaluation, and Molecular Modeling of Donepezil and $\mathrm{N}$-[(5-(Benzyloxy)-1-methyl-1H-indol-2-yl)methyl]-N-methylprop-2-yn-1-amine Hybrids as New Multipotent Cholinesterase/Monoamine Oxidase Inhibitors for the Treatment of Alzheimer's Disease. J. Med. Chem. 2011, 54, 8251-8270. [PubMed]

13. Samadi, A.; Chioua, M.; Bolea, I.; de los Ríos, C.; Iriepa, I.; Moraleda, I.; Bastida, A.; Esteban, G.; Unzeta, M.; Gálvez, E.; et al. Synthesis, biological assessment and molecular modeling of new multipotent MAO and cholinesterase inhibitors as potential drugs for the treatment of Alzheimer's disease. Eur. J. Med. Chem. 2011, 46, 4665-4668. [CrossRef] [PubMed]

14. Ismaili, L.; Refouvelet, B.; Benchekroun, M.; Brogi, S.; Brindisi, M.; Gemma, S.; Campiani, G.; Filipic, S.; Agbaba, D.; Esteban, G.; et al. Multitarget compounds bearing tacrine- and donepezil-like structural and functional motifs for the potential treatment of Alzheimer's disease. Prog. Neurobiol. 2016. [CrossRef] [PubMed]

15. Decker, M. Novel inhibitors of acetyl- and butyrylcholinesterase derived from the alkaloids dehydroevodiamine and rutaecarpine. Eur. J. Med. Chem. 2005, 40, 305-313. [CrossRef] [PubMed]

16. Huang, G.; Kling, B.; Darras, F.H.; Heilmann, J.; Decker, M. Identification of a neuroprotective and selective butyrylcholinesterase inhibitor derived from the natural alkaloid evodiamine. Eur. J. Med. Chem. 2014, 81, 15-21. [CrossRef] [PubMed] 
17. Darras, F.H.; Wehle, S.; Huang, G.; Sotriffer, C.A.; Decker, M. Amine substitution of quinazolinones leads to selective nanomolar AChE inhibitors with “inverted" binding mode. Bioorg. Med. Chem. 2014, 22, 4867-4881. [CrossRef] [PubMed]

18. Benchekroun, M.; Ismaili, L.; Pudlo, M.; Luzet, V.; Gharbi, T.; Refouvelet, B.; Marco-Contelles, J. Donepezil-ferulic acid hybrids as anti-Alzheimer drugs. Future Med. Chem. 2015, 7, 15-21. [CrossRef] [PubMed]

19. Benchekroun, M.; Bartolini, M.; Egea, J.; Romero, A.; Soriano, E.; Pudlo, M.; Luzet, V.; Andrisano, V.; Jimeno, M.-L.; López, M.G.; et al. Novel Tacrine-Grafted Ugi Adducts as Multipotent Anti-Alzheimer Drugs: A Synthetic Renewal in Tacrine-Ferulic Acid Hybrids. ChemMedChem 2015, 10, 523-539. [CrossRef] [PubMed]

20. Ou, B.; Hampsch-Woodill, M.; Prior, R.L. Development and validation of an improved oxygen radical absorbance capacity assay using fluorescein as the fluorescent probe. J. Agric. Food Chem. 2001, 49, 4619-4626. [CrossRef] [PubMed]

21. Dávalos, A.; Gómez-Cordovés, C.; Bartolomé, B. Extending Applicability of the Oxygen Radical Absorbance Capacity (ORAC-Fluorescein) Assay. J. Agric. Food Chem. 2004, 52, 48-54. [CrossRef] [PubMed]

22. Fang, L.; Kraus, B.; Lehmann, J.; Heilmann, J.; Zhang, Y.; Decker, M. Design and synthesis of tacrine-ferulic acid hybrids as multi-potent anti-Alzheimer drug candidates. Bioorg. Med. Chem. Lett. 2008, 18, 2905-2909. [CrossRef] [PubMed]

23. Ellman, G.L.; Courtney, K.D.; Andres, V.; Feather-Stone, R.M. A new and rapid colorimetric determination of acetylcholinesterase activity. Biochem. Pharmacol. 1961, 7, 88-95. [CrossRef]

24. Decker, M.; Krauth, F.; Lehmann, J. Novel tricyclic quinazolinimines and related tetracyclic nitrogen bridgehead compounds as cholinesterase inhibitors with selectivity towards butyrylcholinesterase. Bioorg. Med. Chem. 2006, 14, 1966-1977. [CrossRef] [PubMed]

25. Esquivias-Pérez, M.; Maalej, E.; Romero, A.; Chabchoub, F.; Samadi, A.; Marco-Contelles, J.; Oset-Gasque, M.J. Nontoxic and neuroprotective $\beta$-naphthotacrines for Alzheimer's disease. Chem. Res. Toxicol. 2013, 26, 986-992. [CrossRef] [PubMed]

26. Di, L.; Kerns, E.H.; Fan, K.; McConnell, O.J.; Carter, G.T. High throughput artificial membrane permeability assay for blood-brain barrier. Eur. J. Med. Chem. 2003, 38, 223-232. [CrossRef]

27. Lemes, L.F.N.; de Andrade Ramos, G.; de Oliveira, A.S.; da Silva, F.M.R.; de Castro Couto, G.; da Silva Boni, M.; Guimarães, M.J.R.; Souza, I.N.O.; Bartolini, M.; et al. Cardanol-derived AChE inhibitors: Towards the development of dual binding derivatives for Alzheimer's disease. Eur. J. Med. Chem. 2016, 108, 687-700. [CrossRef] [PubMed]

28. Cornish-Bowden, A. A Simple graphical method for determining the inhibition constants of mixed, uncompetitive and non-competitive inhibitors (Short Communication). Biochem. J. 1974, 137, 143-144. [CrossRef] [PubMed]

29. Silverman, R.B. The Organic Chemistry of Enzyme-catalyzed Reactions; Academic Press: San Diego, CA, USA, 2000.

30. Sugano, K.; Hamada, H.; Machida, M.; Ushio, H. High Throughput Prediction of Oral Absorption: Improvement of the Composition of the Lipid Solution Used in Parallel Artificial Membrane Permeation Assay. J. Biomol. Screen. 2001, 6, 189-196. [CrossRef] [PubMed]

31. Wohnsland, F.; Faller, B. High-Throughput Permeability pH Profile and High-Throughput Alkane/Water $\log$ P with Artificial Membranes. J. Med. Chem. 2001, 44, 923-930. [CrossRef] [PubMed]

Sample Availability: Samples of the compounds 3A-C and 4A-C are available from the authors. 